\title{
The role of regulation in medical student learning in small groups: Regulating oneself and others' learning and emotions
}

\author{
Susanne P. Lajoie ${ }^{a}, *$, Lila Lee ${ }^{a}$, Eric Poitras ${ }^{b}$, Mandana Bassiri ${ }^{a}$, Maedeh Kazemitabar ${ }^{a}$, \\ Ilian Cruz-Panesso ${ }^{a}$, Cindy Hmelo-Silver ${ }^{c}$, Jeffrey Wiseman ${ }^{\mathrm{d}}$, Lap Ki Chan ${ }^{\mathrm{e}}$, Jingyan Lu ${ }^{\mathrm{f}}$ \\ ${ }^{a}$ McGill University, Department of Educational and Counselling Psychology, 3700 McTavish Street, Montreal, Quebec H3A 1Y2, Canada \\ ${ }^{\mathrm{b}}$ University of Utah, College of Education, 1721 Campus Center Drive, SAEC 3202, Salt Lake City, UT 8411, United States \\ ' Indiana University, Center for Research on Learning and Technology, School of Education, 1900 East Tenth Street, Bloomington, IN 47406-7512, United States \\ ${ }^{\mathrm{d}}$ McGill University, Centre for Medical Education, 1110 Pine Avenue West, Montreal, Quebec H3A 1A3, Canada \\ e University of Hong Kong, 2/F, William Mong Block, Faculty of Medicine Building, 21 Sassoon Road, Pokfulam, Hong Kong Special Administrative Region \\ ${ }^{\mathrm{f}}$ Division of Information and Technology Studies, Faculty of Education, The University of Hong Kong, RunMe Shaw 114, Pokfulam Road, Hong Kong Special Administrative Region
}

\section{A R T I C L E I N F O}

\section{Article history:}

Available online 22 January 2015

\section{Keywords:}

Metacognition

Co-regulation

Social-emotional interactions

Computer supported collaborative learning

Medical problem based learning

\begin{abstract}
A B S T R A C T
This study examines the role of regulatory processes in medical students as they learn to deliver bad news to patients in the context of an international web-based problem based learning environment (PBL). In the PBL a medical facilitator and students work together to examine video cases on giving bad news and share their perspectives on what was done effectively and what could be done differently. We examine how regulation occurs within this collaboration. A synchronous computer-supported collaborative learning environment ( $\mathrm{CSCL}$ ) facilitated peer discussion at a distance using a combination of tools that included video-conferencing, chat boxes, and a shared whiteboard to support collaborative engagement. We examine regulation along a continuum, spanning from self- to co-regulation, in situations where medical students learn how to manage their own emotions and adapt their responses to patient reactions. We examine the nature of the discourse between medical students and facilitators to illustrate the conditions in which metacognitive, co-regulation and social emotional activities occur to enhance learning about how to communicate bad news to patients.
\end{abstract}

(c) 2014 Elsevier Ltd. All rights reserved.

\section{Introduction}

The field of metacognition and self-regulated learning continues to evolve and part of this evolution has been to provide operational definitions of constructs in this area that others can agree to (Dinsmore, Alexander, \& Loughlin, 2008; Lajoie, 2008). Rapid changes are occurring in research involving metacognition in general, and "self" and "other" regulation more broadly, requiring careful considerations of operational definitions and methodologies to calibrate the research. We attempt to position our selves in this rapidly changing field by providing a brief review of papers that are influencing our thinking on these concepts. Following a discussion of definitions and methodologies we attempt to apply

\footnotetext{
* Corresponding author. Tel.: +1 (514) 3983429.

E-mail addresses: Susanne.lajoie@mcgill.ca (S.P. Lajoie), lila.lee@mail.mcgill.ca (L. Lee), eric.poitras@utah.edu (E. Poitras), mandana.bassiri@mail.mcgill.ca (M. Bassiri), maedeh.kazemi@mail.mcgill.ca (M. Kazemitabar), ilian.cruz-panesso@ mail.mcgill.ca (I. Cruz-Panesso), chmelosi@indiana.edu (C. Hmelo-Silver), Jeffrey. wiseman@mcgill.ca (J. Wiseman), lapki@hkucc.hku.hk (L.K. Chan), jingyan@hku.hk (J. Lu).
}

current assumptions to our research on metacognition, self-regulation, co-regulation and the role of social-emotional interactions in medicine.

\subsection{Flexing definitions}

\subsubsection{Metacognition}

Flavell (1979) created the term metacognition to refer to thinking about one's own thinking. He further elaborates that through experience we learn what to monitor, how to set goals to achieve understanding, which strategies to use to achieve our goals, and finally how to evaluate our successes and failures. Metacognition is understood as being comprised of the knowledge of one's own learning and a set of monitory/regulation activities that help control one's learning (Flavell, 1979; Schraw \& Moshman, 1995). Strategic use of metacognitive knowledge to achieve cognitive goals and the regulation and control of cognitive processes are reliant on metacognitive activity (Alexander, Carr, \& Schwanenflugel, 1995). The components of which can be distinguished at various levels of granularity, thus lending itself to methodological 
innovations for studying such activity (Meijer, Veenman, \& van Hout-Wolters, 2006).

\subsubsection{Self-regulation}

Baker and Brown (1984) coined the term self-regulation when they discussed the difference between metacognitive knowledge and the regulatory mechanism needed to know what one knows. Individuals use cognitive and metacognitive regulatory processes to plan, perform, and maintain their desired objectives (Volet, Vauras, Khosa, \& Iisakala, 2013). Self-regulation serves a purpose in academia, in that it can be applied to learning, and hence the term self-regulated learning (SRL) was formed (Corno \& Mandinach, 1983; Zimmerman, 1986) referring to monitoring and controlling ones' own learning (Dinsmore et al., 2008; Pintrich, 2000, 2004; Zimmerman \& Schunk, 2001). SRL is a recursive process that occurs at all stages of a learning episode. Some refer to SRL as an event that unfolds dynamically where individual SRL processes fluctuate in terms of frequency during the learning task (Azevedo, Moos, Johnson, \& Chauncey, 2010). Students are self-regulated to the degree that they are cognitively, motivationally, emotionally, and behaviorally active participants in their own learning process (Azevedo et al., 2010; Bandura, 1977; Loyens, Magda, \& Rikers, 2008; Zimmerman, 1986; Zimmerman \& Schunk, 2001).

Contemporary SRL theories have developed considerably in the past decade in scope and complexity (Pintrich, 2004; Schunk, 2005; Winne \& Hadwin, 2008; Zimmerman, 2006, 2008; Zimmerman \& Schunk, 2001, 2011). Although SRL theories share common assumptions across domains of study, there is agreement that self-regulation and SRL are affected by the domain, task (Alexander, Dinsmore, Parkinson, \& Winters, 2011; Meijer et al., 2006; Lajoie \& Poitras, 2014; Poitras \& Lajoie, 2013) and context (Hadwin \& Järvelä, 2011; Järvelä and Hadwin, 2013; Volet et al., 2013).

Kaplan's (2008) idea of "multidimensional conceptual space of self-regulated action" is an "umbrella" concept for metacognition and self-regulation. The similarities between self-regulation and metacognition underline an important conceptual link between the constructs, where, as individuals make an effort to monitor their thoughts and actions, they takes actions to control them (Dinsmore et al., 2008). Metacognition and self-regulation are not mutually exclusive; they are "subtypes of the same general phenomenon of self-regulated action (Schwartz, Scott, \& Holzberger, 2013).

A key mechanism in improving metacognition or self-regulation is the ability to observe and listen to other perspectives. Social context plays an important role in the regulatory process (Hadwin and Oshige, 2011). For instance, the social environment may include modeling from teacher and/or peer guidance (Hadwin, Wozney, \& Pontin, 2005; McCaslin \& Hickey, 2001; Palinscar \& Brown, 1984). Attending to multiple perspectives can lead to shifts in one's knowledge that can lead to new forms of self-directed self-regulatory activities that are more informed. Volet, Vauras and Salonen (2009) describe self-regulation as the use of cognitive and metacognitive regulatory process by which individuals plan, put into action and maintain their objectives; whereas, social regulation is described as a process that requires individuals to regulate each other's cognitive and metacognitive processes reciprocally (Khosa, 2014).

\subsection{Co-regulation and social-emotional interactions}

To understand the regulation of collaborative learning processes, both self and social forms of regulation need to be considered. More focus needs to be placed on the inter-relational aspects and functioning of metacognition to understand group dynamics as complex interactions across various systemic levels (Volet, Vauras \& Salonen, 2009; Khosa, 2014).

\subsubsection{Co-regulation}

The co-regulation construct is grounded in social-constructivist theory based on Vygotsky's (1978) view that higher psychological processes are socially embedded or contextualized. These processes are internalized through social interaction (McCaslin, 2009; Wertsch \& Stones, 1985). Co-regulation attributes social interaction and instructional context to effective SRL (Hadwin, Järvelä, \& Miller, 2011).

Co-regulation encompasses the collaboration of group members as a transitional process towards self-regulation (Hadwin \& Oshige, 2011; Järvelä and Hadwin, 2013). Group members work together in a social environment to support and/or scaffold individual participation and learning (McCaslin, 2004). Each member acts in their own self regulating interests, but may participate in socially regulating each other's learning (Volet, Summers, \& Thurman, 2009) through questioning, prompting, and restarting (Järvelä and Hadwin, 2013). Co-regulation requires social interactions between group members to ease the cognitive demands of the task by sharing the metacognitive demands of monitoring, evaluating, and regulating the task processes (Hadwin \& Oshige, 2011; Lajoie \& Lu, 2012).

The next step in the regulation continuum is shared regulation that focuses on collective interactions and collaboration as a whole, rather than knowledge transfer or cognition on an individual level through interpersonal interactions (Hadwin \& Oshige, 2011). Shared regulation involves the co-construction of goals and standards, where regulation is distributed and shared with multiple ideas and perspectives being assessed and negotiated towards a mutual agreement (Hadwin \& Oshige, 2011; Järvelä and Hadwin, 2013; Volet \& Vauras, 2013). Learners' mutual regulatory activities during problem solving session can provide insights to understand how members engage in productive collaboration.

The consensus in the literature is that appropriate scaffolding of group learning activities can lead to regulation. Collaborative learning groups involve several self-regulating individuals with different levels of knowledge and skills, where each participant may have started with incompatible goals. As such, it is important to understand how group members work together in negotiating, coordinating and regulating their collaborative activities to reach a common understanding of the task and shared goal(s): how are learners using effective strategies, co-constructing knowledge and working productively to complete the task (Hadwin et al., 2011; Volet et al., 2013)? Chan (2012) described productive group interactions as involving students' self-regulating their own learning, and co-regulating the learning of others in the group. As such, the group as a united body influences the students' own regulation and cognition (Khosa, 2014).

Hadwin et al. (2011) state that even though there is growing awareness that regulation is best understood as both an individual and a social process, more empirical evidence on social regulatory processes pertaining to higher order learning is needed. An added complexity to understanding such interactions is the role of socialemotional interactions in the regulatory process. We discuss this role below.

\subsubsection{Social-emotional interactions and their role in regulation}

Group members regulate their cognition, emotions, and motivation together, through their collective responsibility to meet the task requirements. Individual group members contribute to the construction of the group's shared cognitions and emotional stability (Thompson \& Fine, 1999) through negotiation, reconsidering, explaining, listening and showing respect. 
Emotion regulation (ER) is critical for successful collaboration towards the achievement of the learning task goals (Järvenoja \& Järvelä, 2009). ER is a type of self-regulation (Tice \& Bratslavsky 2000) that refers to "the processes by which individuals' influence which emotions they have, when they have them, and how they experience and express these emotions" (Gross \& Thompson, 2007, p. 275). ER can dampen, intensify, or maintain an emotional reaction (Rimé, 2007). The locus of ER in a social setting can be intrinsic or extrinsic (Fox \& Calkins, 2003). Intrinsic ER refers to the regulation of one's own emotions, whereas extrinsic ER focuses on ER strategies applied to regulate others' emotions within a socio-emotional context. The latter form entails approximating the emotional consequences for another person as well as managing one's own emotions (Gross \& Thompson, 2007).

The social setting can induce positive or negative emotions and as such the socio-emotional aspects can contribute to advanced interaction and engagement in the group co-construction of knowledge (Hadwin \& Oshige, 2011; Volet \& Vauras, 2013). The impact of emotion on learning is complex (Pekrun \& Linnenbrink-Garcia, 2014) and researchers have begun to examine how emotions impact both cognitive development and psychological health. Each individual in the group has emotions they experience and thus emotional regulation is important to the learning environment.

Positive socio-emotional interactions include the extent to which the group members express mutual respect, caring and support to each other (Rogat \& Linnenbrink-Garcia, 2011). Negative socio-emotional interactions may result both from a lack of opportunity to develop skills for group work (Stevens \& Campion, 1994) and from frustration experienced when dealing with group challenges (Järvenoja \& Järvelä, 2009). Research shows that there are significant consequences for the overall quality of group learning opportunities when members do not respect one another or are overly critical of each other's contributions (Webb, Ing, Kersting, \& Nemer, 2006). These challenges may originate from individual differences (e.g. conflicting goals, different levels of interest, multiple cognitive perspectives) or interpersonal dynamics (e.g. different communication styles). Since both positive and negative interactions have a role in the development of metacognition (Garrison, Anderson \& Rourke, 2000), increased study into the impact of emotion on co-regulation is needed.

\subsection{The international computer supported collaborative problem based learning $(P B L)$ environment}

The research that we describe in this paper is part of a larger study that investigated the use of technology to facilitate collaborative PBL activities in an international group of medical students and facilitators (see Lajoie et al., 2014). We restrict this paper to our exploration of the metacognitive, cognitive and social-emotional regulatory activities that occur during this PBL activity.

\subsubsection{Context}

The medical curriculum covered in the PBL was how to conduct a medical interview when communicating bad news to a patient. Bad news, in this context, refers to providing information that may affect a patient's view of his or her future well being (Buckman, 1984, 2005). PBL (Barrows \& Tamblyn, 1986; HmeloSilver \& Barrows, 2008) is a special inquiry based approach that supports collaborative knowledge construction. During PBL learners develop content knowledge, effective problem-solving and critical analysis skills that results in flexible knowledge (Hmelo-Silver, 2004; Hmelo-Silver \& DeSimone, 2013). The expert facilitator's objective is to guide the discussion towards achieving the goal of the collaborative session.
Technology was used to support an international group of medical students and facilitators in Canada, Hong Kong and the US, who worked together in a PBL to co-construct an understanding of how to communicate bad news to patients. Web conferencing software supported the group through synchronous video interaction and shared applications. Video streams enabled group members to view each other's reactions and facial expressions, which were relevant in simulated instructional scenarios such as the ones reviewed in the following sections. Chat windows allowed group members to review the transcript of their own discussions to reflect on key aspects of an argument.

Our claim is that an online-PBL can facilitate metacognition and co-regulation by establishing the types of social-emotional interactions that lead to effective collaborations in the medical domain, particularly with respect to situations that require empathy and forethought. The literature has shown that positive emotional engagement within social contexts leads to higher group functioning, as manifested in mutual trust, respect, and shared agreements (Rogat \& Linnenbrink-Garcia, 2011). Since both positive and negative interactions have a role in the development of metacognition (Garrison, Anderson, \& Archer, 2000) we explore how such interactions impact co-regulation at the group level. Training novice physicians to deliver bad news to critically ill patients requires sensitivity. We examine the manner in which metacognitive processes,, co-regulation, and social-emotional skills evolve over a two day PBL training intervention and examine the interrelationship among theses constructs in the group discourse.

Mixed groups of students from Canada and Hong Kong worked with medical facilitators from each country. The PBL groups worked together on 2 video cases that demonstrated physicians giving patients the bad news regarding their HIV test results. An expert PBL facilitator supported the medical facilitators from each country by monitoring the thread of discussion in the chat window and prompting them to engage in a certain type of discourse.

This study addresses the following research questions:

1. Does the nature and frequency of metacognitive activity change over the duration of the PBL (from session 1 on Day 1 to session 2 on Day 2)?

2. Does the nature and frequency of co-regulation change over the duration of the PBL (from session 1 on Day 1 to session 2 on Day 2)?

3. What is the nature and frequency of social-emotional interactions over the duration of the PBL (from session 1 on Day 1 to session 2 on Day 2)?

4. What is the relationship between metacognition \& co-regulation \& social emotional interactions as identified in the PBL activities?

\section{Methods}

\subsection{Participants}

The PBL group consisted of 7 volunteers: 4 medical students with a mean of 2.5 years experience volunteered, 2 from Canada ( 1 male, 1 female) referred to as $\mathrm{C} 1$ and $\mathrm{C} 2$ respectively, and 2 from Hong Kong (2 males) named HK1 and HK2; two experienced male physician educators (one from each country) referred to as medical facilitators (CF and HKF); and, a female expert in PBL facilitation from the USA referred to as the expert PBL facilitator.

\subsection{Procedure and materials}

The instructional environment consisted of 5 on-line modules that occurred over consecutive days that were supported through Adobe Connect 9 web-conferencing software. For the purpose of 
this paper we analyze data from modules 2 and 3 that addressed the interactions during the PBL intervention to determine the different types of regulatory processes that occurred in the group. Modules 1 and 4 consisted of pre and post-tests of individual performance of medical students giving bad news to standardized patients (patients who were given a script of how to act based on specific physician actions). These data are not analyzed for this paper since we are not addressing individual performance. A debriefing occurred on day 5 and was simply informational rather than part of the group learning activity.

\subsubsection{Intervention (PBL sessions)}

Two PBL sessions were designed to help the 4 medical students understand the principles behind how to conduct a medical interview when giving bad news to the patient. The PBL teacher (either the Canadian or Hong Kong physician depending on the case) is a facilitator of student learning. The role of the facilitator is to help monitor group discussions, guide students in the learning process, push them to think deeply, and model the kinds of questions that students need to be asking themselves (Hmelo-Silver \& Barrows, 2006). The facilitator's interventions diminish as students progressively take on responsibility for their own learning. The instructor assigns one student facilitator to lead the discussions and another student as note-taker, while the remaining two students continue the group discussion. Student roles change from one PBL to the next so that students take turns at facilitating the discussion, note taking, etc.

The PBL sessions followed a pre-test of breaking bad news to a standardized patient. The two PBL sessions dealt with the same objectives but provided learners with two different contexts by providing video cases specific to each country. The first PBL consisted of a Canadian patient case and was moderated by $\mathrm{CF}$ whereas the second PBL consisted of Chinese patient case moderated by a HKF. In both video cases the physician communicated a diagnosis of HIV to his respective patient.

The underlying curriculum model used to support the PBL was based on the SPIKES algorithm (Buckman, 2005; Fishel \& Hochman,
2009) created by physician-instructors to help teach best approaches for disclosing unfavorable health related news. The algorithm helps physicians respond appropriately to the emotional reactions of patients (Baile et al., 2000) by establishing the appropriate Setting, testing the Perception of what patients know, Inviting patients to ask questions, providing medical Knowledge, Empathy when needed, and Summary of the news. Each step has a set of rules to establish effective communication with the patient.

The medical facilitators used a SPIKES protocol to illustrate best practices for communicating bad news. PBL prompts were designed in collaboration with an expert in PBL and were used similarly by both instructors. The PBL expert synchronously supported the two medical facilitators during the PBL sessions through a private chat window integrated in Adobe Connect 9, which medical students could not view or access. She could hear and see the entire PBL session as it proceeded. The video case vignettes served as the context to trigger specific learning objectives in the PBL sessions, where medical facilitators helped students to: (1) identify difficulties in communicating bad news to a patient with strategies for addressing these issues; (2) provide an approach to giving bad news; (3) use the SPIKES model to analyze a video of a bad news communication session; and (4) discuss and reflect on how the model may have to respond to context, culture and language barriers.

\subsubsection{Adobe Connect 9}

Adobe Connect 9 was used to support the computer collaboration since it had embedded tools to support collaborative engagement through audio, video, and text including notes and chats (Fig. 1). All participants used a wired configuration to control for bandwidth speed and technical difficulties. All participants used headsets with microphones. Each individual was located in a different room and interacted with the other participants only through Adobe Connect 9. Medical students received training on how to use the software prior to the commencement of the study.

Control of the Adobe Connect 9 interface was in the hands of the medical- facilitators (and researchers) who could choose to add

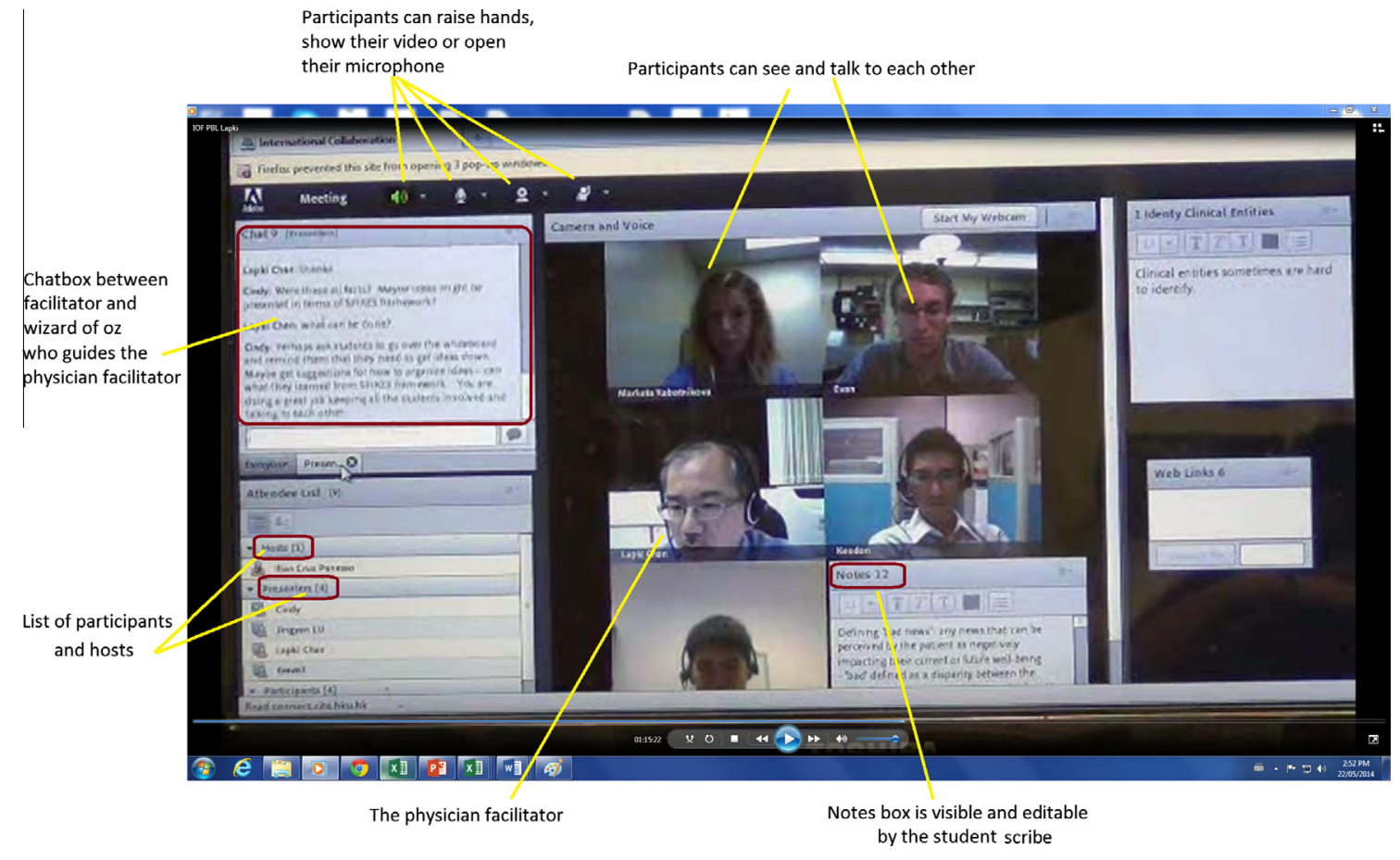

Fig. 1. Description of features of Adobe Connect 9 used to support the PBL. 
elements such as note/chat windows, play videos, and share files according to the needs of the meeting. Participation using Adobe Connect 9 was facilitated by using icons to raise hands to speak, to show agreement or disagreement during the meeting, or request that someone speak louder or slower. The software is platformindependent and does not need to be downloaded to access the online meetings; medical students received a link sent by email. The software's recording capabilities allowed for independent records of all content sources (audio, video, chats, and notes).

\subsection{Research design and analysis}

This pilot study utilized an exploratory mixed methods approach. Frequency data and qualitative excerpts provide answers to questions $1-3$, while question 4 was addressed through the use of a sequential pattern mining technique. A single case study design (Yin, 2009) was used that examines a PBL group over two days. A single case study is used here as a revelatory case to describe the PBL in depth by looking at issues of metacognition, co-regulation and social-emotional interactions. The case is unique since it uses technology to support an international PBL where the mainstream culture is a medical group of students and medical facilitators. The data sources consisted of the PBL group discourse that occurred over two sessions.

The PBL sessions were video taped and screen recorded. The total duration of the PBL intervention was $264 \mathrm{~min}$ (124 min for the first and $140 \mathrm{~min}$ the second session). The discourse of the PBL groups was transcribed verbatim and analyzed for evidence of metacognition, co-regulation and socio-emotional activities in the problem solving activity. There are 532 dialogue turns of participant speech in the corpus (see Tables 1-3 for codes). The corpus data were analyzed based on turn-taking for metacognitive activities ( 7 codes) and social-emotional interactions ( 5 codes). Co-regulation was coded using a coarser-grain size of episodes (217 episodes and 5 codes). Episodes pertain to one specific idea and consist of a minimum of 2 turns and have no maximum number of turns (Iislaka, Vauras, Lehtinen, \& Salonen, 2011). As such, the number of co-occurrences considered is $7 \times 5,5 \times 5$, and $7 \times 5$, respectively.

Following is a detailed description of the coding categories. We first describe the metacognitive and co-regulation codes followed by the social-emotional regulatory codes. The inter-rater reliability

Table 1

Metacognitive coding definitions and examples.

\begin{tabular}{|c|c|c|}
\hline Codes & Definition & Examples \\
\hline Orientation & $\begin{array}{l}\text { - Activating prior knowledge } \\
\text { - Establishing task demands } \\
\text { - Hypothesizing } \\
\text { - Identifying/repeating important information } \\
\text { - Studying or rereading } \\
\text { - Filling in values/establishing givens }\end{array}$ & $\begin{array}{l}\text { And of course we have to } \\
\text { note the emotion and the condition of the patient }\end{array}$ \\
\hline Planning & $\begin{array}{l}\text { - Looking for particular information } \\
\text { - Organizing thoughts by self-questioning } \\
\text { - Resuming } \\
\text { - Subgoaling } \\
\text { - Using external source to get explanation } \\
\text { - Backward reasoning } \\
\text { - Decision to change strategy } \\
\text { - Form action plan } \\
\text { - Simplify problem }\end{array}$ & $\begin{array}{l}\text { Say if the patient enters in the consultation room, } \\
\text { and she is very depressed, so may be at that time, } \\
\text { it may not very be appropriate for us to break the new at that moment }\end{array}$ \\
\hline Executing & $\begin{array}{l}\text { - Commenting on explanation } \\
\text { - Note-taking, underlining, highlighting } \\
\text { - Reacting to question of experimenter } \\
\text { - Estimating } \\
\text { - Executing action plan } \\
\text { - Transferring one representation into another }\end{array}$ & Yeah, it makes a lot of sense \\
\hline Monitoring & $\begin{array}{l}\text { - Checking memory capacity } \\
\text { - Claiming (partial) understanding } \\
\text { - Comprehension failure } \\
\text { - Error detection } \\
\text { - Found required information } \\
\text { - Information required not found } \\
\text { - Noticing inconsistency, confusion, checking plausibility } \\
\text { - Noticing unfamiliar words or terms } \\
\text { - Noticing retrieval failure } \\
\text { - Commenting on task demands or available time } \\
\text { - Claiming progress in understanding } \\
\text { - Give meaning to symbols or formulae } \\
\text { - Noticing differences } \\
\text { - Using former interim outcome }\end{array}$ & I did not find "SPIKES" \\
\hline Evaluation & $\begin{array}{l}\text { - Checking } \\
\text { - Explaining strategy, justifying } \\
\text { - Finding summaries or analogies } \\
\text { - Give up or quit } \\
\text { - Self-critique } \\
\text { - Verifying }\end{array}$ & $\begin{array}{l}\text { Well um our discussion, um the fact that we } \\
\text { have the ... SPIKES of the video and arrived at some conclusion }\end{array}$ \\
\hline Elaboration & $\begin{array}{l}\text { - Concluding } \\
\text { - Connecting } \\
\text { - Inferring } \\
\text { - Paraphrase/summarize }\end{array}$ & $\begin{array}{l}\text { But I still think she everything she did was } \\
\text { great, but there is just something there is missing, I thought }\end{array}$ \\
\hline No code & & \\
\hline
\end{tabular}


Table 2

Co-regulatory coding scheme.

\begin{tabular}{|c|c|c|c|}
\hline Categories & Codes & Definitions & Examples \\
\hline \multicolumn{4}{|c|}{ Co-regulatory episodes (micro-level) } \\
\hline \multirow[t]{2}{*}{ Facilitate } & Activate & $\begin{array}{l}\text { Activating a new construct in line } \\
\text { with previous direction }\end{array}$ & $\begin{array}{l}\text { HK1: Because he is using a lot of sensory muscles and his eyes are wide you know as if he is popping out } \\
\text { of the socket. But um how would that, what does that body language convey, like } \\
\text { C1: Above all this, nervousness and anxiety. I would say }\end{array}$ \\
\hline & Confirm & $\begin{array}{l}\text { Confirming that the previous } \\
\text { direction is correct }\end{array}$ & $\begin{array}{l}\text { HKF: Well now I think you raised a point because it sounded all the same to you, you were almost saying } \\
\text { that his voice is monotonous } \\
\text { C2: "C1" there, yea.ye }\end{array}$ \\
\hline \multirow[t]{3}{*}{ Inhibit } & Slow & $\begin{array}{l}\text { Slowing down a continuation the } \\
\text { previous direction }\end{array}$ & $\begin{array}{l}\text { HKF: So C1you, you um, you didn't look at um "SPIKES" model before this you know this videoconference } \\
\text { session. So if you were not exposed to this model at all, um do you think you would have made as much } \\
\text { observation as we did today? Well do you think the model helps? } \\
\text { C1: I think it is difficult to say. I do think the model help, but it helped me more for categorizing I guess } \\
\text { for the what }\end{array}$ \\
\hline & Change & $\begin{array}{l}\text { Changing the direction of previous } \\
\text { activity }\end{array}$ & $\begin{array}{l}\text { HK2: O um, I was not using this model, I was just yeah, as you say, just think of a way } \\
\text { HKF: You are not using it, "HK1"? Would you use it like you say? }\end{array}$ \\
\hline & No code & & \\
\hline
\end{tabular}

Table 3

Social emotional interactions coding and examples.

\begin{tabular}{|c|c|c|c|}
\hline Valence & Social presence & Subcategories & Examples \\
\hline \multirow[t]{4}{*}{$\begin{array}{l}\text { Positive social } \\
\text { emotional } \\
\text { interactions }\end{array}$} & $\begin{array}{l}\text { Affective Social Presence (ASP) (expressions conveying emotions, } \\
\text { Showing respect and honour to others, polite disagreement) }\end{array}$ & $\begin{array}{l}\text { - Expression of } \\
\text { emotions }^{\mathrm{a}} \\
\text { - Use of humou } \\
\text { - Self-disclosure } \\
\text { - Mutual Respect }^{\mathrm{a}, \mathrm{b}} \\
\text { - Interpersonal } \\
\text { Sensitivity }^{\mathrm{c}}\end{array}$ & $\begin{array}{l}\text { I am sorry to interrupt, can you finish your } \\
\text { sentence please? } \\
\text { V has a tough job, he is scribing and } \\
\text { answering questions at the same time }\end{array}$ \\
\hline & $\begin{array}{l}\text { Interactive Social Presence (ISP) (Complimenting, expressing } \\
\text { appreciation, encouraging contributions) }\end{array}$ & $\begin{array}{l}\text { - Continuing a } \\
\text { thread }^{\mathrm{a}} \\
\text { - Asking questions }\end{array}$ & You are right. This seems to be important \\
\hline & & $\begin{array}{l}\text { - Expressing } \\
\text { agreement }^{\mathrm{a}} \\
\text { - Giving } \\
\text { information } \\
\text { - Taking the lead }\end{array}$ & $\begin{array}{l}\text { Does anybody know how we should deal } \\
\text { with a translator? }\end{array}$ \\
\hline & $\begin{array}{l}\text { Cohesive Social Presence (CSP) (referring to the group using plural } \\
\text { pronouns; e.g. we) }\end{array}$ & $\begin{array}{l}\text { - Using inclusive } \\
\text { pronouns } \\
\text { - Phatics, salutations }\end{array}$ & Let us work this issue out together \\
\hline \multirow[t]{3}{*}{$\begin{array}{l}\text { Negative social } \\
\text { emotional } \\
\text { interactions }\end{array}$} & Internal factors (Not listening actively, showing distractive behaviours) & $\begin{array}{l}\text { - Negative criticism }{ }^{\mathrm{b}} \\
\text { - Low group } \\
\text { cohesion }^{\mathrm{b}}\end{array}$ & $\begin{array}{l}\text { This is a Cantonese thing, you guys can't } \\
\text { help out }\end{array}$ \\
\hline & & $\begin{array}{l}\text { - Discouraging } \\
\text { others' participation }^{\mathrm{b}} \\
\text { - Passive listening }\end{array}$ & $\begin{array}{l}\text { Sorry I don't have my notes here. Please } \\
\text { continue while I try to find them }\end{array}$ \\
\hline & $\begin{array}{l}\text { External factors } \\
\text { No code }\end{array}$ & - Technology $^{\mathrm{d}}$ & $\begin{array}{l}\text { I lost audio for a few seconds and did not } \\
\text { hear you }\end{array}$ \\
\hline
\end{tabular}

\footnotetext{
a Garrison et al. (2000) and Authors.

b Rogat and Linnenbrink-Garcia (2011).

c Lopes et al. (2005).

${ }^{\mathrm{d}}$ Derived from our data.
}

(Pearson correlation coefficient) for the metacognitive codes is $79 \%, 84.5 \%$ for the co-regulatory and $91.5 \%$ for the social-emotional codes. A principal coder and a trained coder performed coding. A disagreement was counted when two coders assign different codes for a turn. For co-regulatory episodes, the start and end of an episode were not required to be exact as long as the episode is identified with the same code. The majority of disagreements were solved by negotiation especially for metacognition.

\subsubsection{Metacognitive, co-regulation and social-emotional codes}

The data were coded based on an adaption of the super ordinate categories of metacognitive activity (see Meijer et al., 2006) those being orientation, planning, executing, monitoring, evaluation, and elaboration. The theoretical codes were consistent with Meijer et al.'s taxonomy but altered to be more consistent with problem solving rather than a simple reading task. For example, "Reading parts of text very carefully" was translated into "reading parts of the problem statement very carefully" and was coded as orientation rather than execution. Unlike Meijer et al.'s works, think aloud's were not used in this study. Rather the group's discourse patterns were examined and patterns were identified that represented sensible sequences of metacognitive activities. Establishing the correlation of the occurrences of these sequences with learning about how to communicate bad news may shed light on the metacognitive strategies that contribute to learning.

The coding definitions are provided in Table 1 along with examples from our data that reflect these codes.

We coded each transcript for metacognitive activity. The unit of analysis was the speaker turn. If a turn demonstrated more than one type of metacognitive activity it was coded more than once.

Co-regulation is a complex construct that consists of both cognitive and metacognitive activities. We concur with Hadwin et al. (2011) that co-regulation requires purposeful mediation of planning, monitoring, evaluating, or changing specific beliefs and strategies for motivation, cognition, or behavior. We agree with Volet, Vauras and Salonen (2009) that co-regulation consists of 
episodes in which multiple group members verbally contribute to the task at hand.

Volet and Summers (2013) challenge researchers to consider both the general and context specific application of coding systems in social regulation research. The more specific or granular (Azevedo, 2009; Chan, 2012) a coding scheme, the more precise the contextualized examination of the learning task in question. We take these contextual issues into consideration while coding.

Our co-regulation coding is based on a template derived from Iiskala, Vauras, Lehtinen, and Salonen (2011). Although Iiskala et al.'s (2011) coding referred to socially shared metacognition Hadwin and Oshige (2011) had redefined these constructs as coregulation since peers were mediating each other's metacognition and cognition actions. We use empirical indicators to contextualize co-regulation codes to specifically address transition points at the episode level between instances. As well as contextualizing the coding scheme, the specific codes enabled a precise method of highlighting the function of the episode level in the data. The coding involved the social nature and function of co-regulatory talk in the contextual flow of cognitive activity.

Table 2 summarizes the co-regulatory categories that facilitate (activate, confirm) and inhibit (slow, change, and stop) group understanding. The PBL sessions were organized as a long discussion and participants would not stop the course of a dialogue without introducing new ideas. Consequently, we did not use Iiskala et al.'s "stop" category since it was not appropriate in our context. Not all individual turns in an episode were co-regulatory however, when turns are taken as a whole within an episode we coded for co-regulation. Anything that fell outside of the co-regulatory episode was counted as "no code". Episodes were coded for co-regulatory episodes of learning to break bad news to patients. Reciprocal turns between members indicate jointly regulated learning processes. For example, in an episode of the Confirm code, a member agrees on another member's delivered information that was shared in a previous turn. That turn can stimulate another member's metacognitive activity toward the same goal(s) or inhibit the metacognitive activity and help students change direction of the discussion to achieve better outcomes.

The primary framework that guided the coding of the socioemotional interactions was the "community of inquiry" model (Garrison et al., 2000). We chose this framework because it provides descriptors for examining interactions from both an emotional and social perspective. We supplemented these codes with work by Rogat and Linnenbrink-Garcia (2011) and Lopes, Salovey, Côté, Beers, and Petty (2005) who looked closely at more nuanced definitions of emotion in dyads or group settings. Qualitative approaches that analyze group discourse within learning sessions can provide valuable insights into the emotions experienced while learning, which can supplement the type of before or after learning captured by questionnaires and self-report data (Pekrun \& Linnenbrink-Garcia, 2014).

Table 3 provides a complete description of the codes for social emotional interactions along with examples and references. The coding protocol was developed in two phases. In the first stage and prior to viewing the videos, we developed a primary list of codes derived from the literature and based on our underlying theory. In the second stage, while analyzing the videos with our preliminary set of codes, we redefined and re-categorized codes and provided relevant examples.

Both positive and negative socio-emotional interactions were coded. The positive socio-emotional interactions refer to any socio-emotional attempt to move the discussion forward towards attainment of the session goal (Rogat \& Linnenbrink-Garcia, 2011). Garrison et al. (2000) argue that the cognitive/metacognitive dimensions are enhanced and sustained by establishing positive socio-emotional regulation within a group. Social presence pertains to the social and/or affective remarks that appear in the group discourse and refers to the development of a supportive environment where participants feel they can comfortably share and express their ideas publically within a collaborative context (Anderson, 2004). Social presence has three macro-level categories, affective, interactive and cohesive (Garrison et al., 2000; Lajoie et al., 2006). Affective social presence includes expression of emotions, use of humor, self-disclosure, mutual respect and interpersonal sensitivity. Interactive Social Presence pertains to socially interactive collaborations such as encouraging contributions, expressing agreement, continuing a thread, asking questions and taking the lead. Cohesive Social Presence includes codes that promote cohesion such as the use of inclusive pronouns and salutations, derived from literature (Lajoie et al., 2006).

Negative socio-emotional interactions undermine group-level discussions (Rogat \& Linnenbrink-Garcia, 2011). This category was divided into two macro-level categories of internal and external factors. Internal negative social emotional codes included negative criticism, low group cohesion, discouraging others' participation and passive listening. External factors referred to technology barriers.

\subsubsection{Data mining procedure}

A data mining technique was applied to analyze the discourse data. In the first stage of the analysis, a sequential pattern mining method was used to assist researchers in detecting relationships of interest between dialogue moves among medical participants in the PBL group. This method is similar to the sequential pattern mining method outlined by D'Mello, Olney, and Person (2010), with the exception that our method focuses on inter-relationships amongst dialogue moves that are coded at different levels of granularity. D'Mello et al. (2010) outline a technique for the discovery of intra-relationships amongst moves by detecting significant transitions between two distinct types of dialogue moves as they occur in serial order across time. The technique outlined in our paper applies similar metrics, albeit with respect to the co-occurrence of two distinct types of dialogue moves with respect to a similar time period.

This pattern mining method is well suited to the analysis of coregulatory mechanisms in tutorial dialogue, given that different coding formalisms are applied to characterize the same corpus of discourse at different levels of granularity, as shown in Fig. 2. The coded episodes of co-regulation occur at a broader grain size because of the need to consider the entire context of a thread of discussion. In contrast, the regulatory behaviors that occur at the level of specific individuals within a group are manifested at the level of individual moves within the thread of discussion (i.e., metacognitive activities, socio-emotional interactions). Although the amount of context that is taken into consideration while coding the discourse data is different, these two distinct events that characterize the discourse occur simultaneously when a type of move is found to occur within a particular episode. As such, there are three possible combinations of co-occurrences based on the processes outlined in our theoretical framework: (1) the inter-relationship amongst co-regulatory episodes and metacognitive activities, (2) co-regulatory episodes and socio-emotional interactions, and (3) the metacognitive activities and socio-emotional interactions. These co-occurring events within the discourse are explored using the sequential pattern mining in the first stage of the analysis in order to find common patterns.

The likelihood metric outlined by D'Mello, Taylor, and Graesser (2007) was adapted to compute the likelihood of co-occurrence between any two moves. The metric as defined to capture intrarelations between discourse moves is defined as the likelihood $(L)$ of a particular move at a given time $\left(M_{t}\right)$ given the next move $\left(M_{t+1}\right)$. See formula below: 


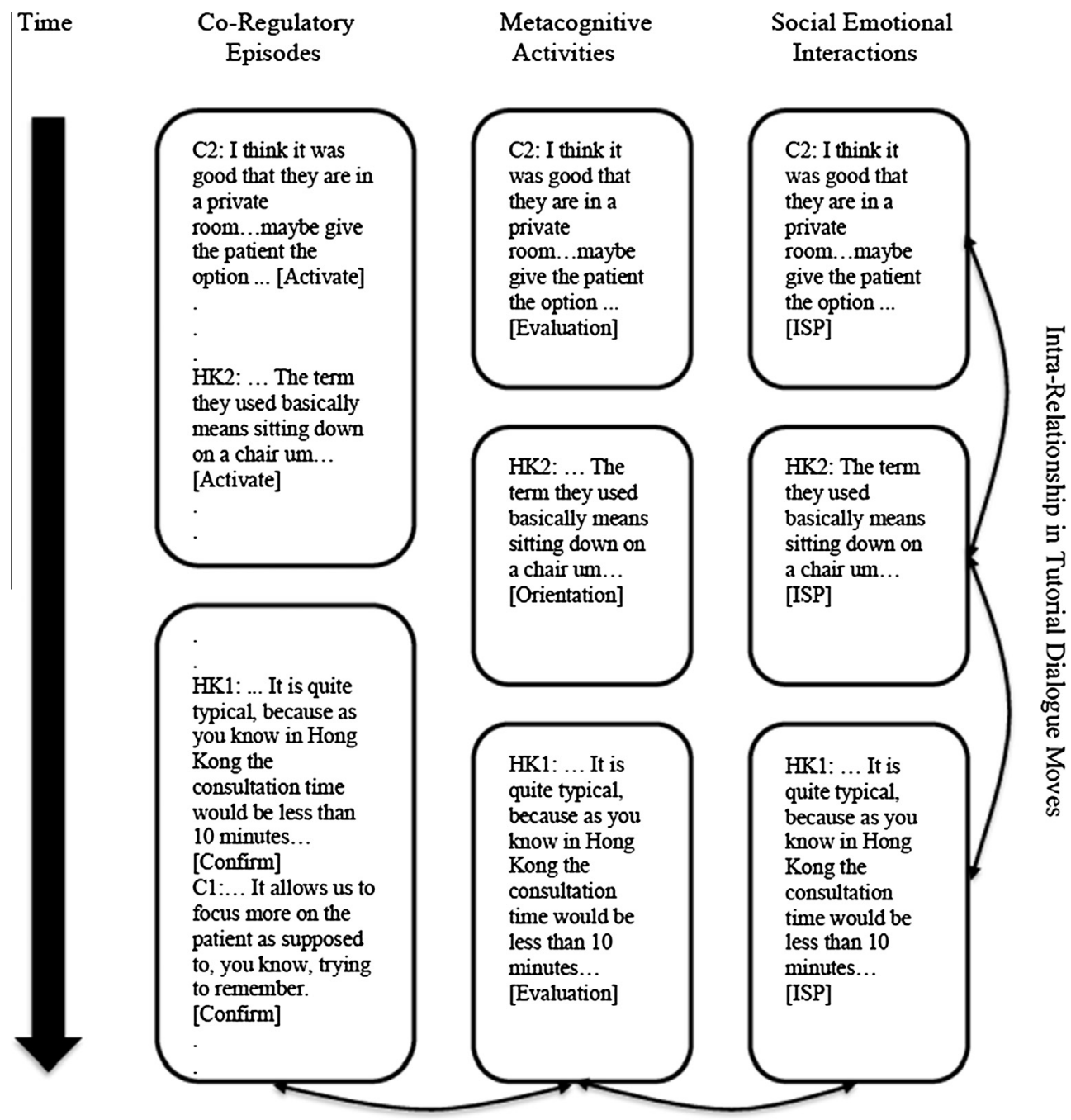

Inter-Relationship in Tutorial Dialogue Moves

Fig. 2. Mining dialogue for inter- and intra-relationships with examples from data.

$L\left(M_{t} \rightarrow M_{t+1}\right)=\frac{\operatorname{Pr}\left(M_{t+1} \mid M_{t}\right)-\operatorname{Pr}\left(M_{t+1}\right)}{1-\operatorname{Pr}\left(M_{t+1}\right)}$

The notation $c$ is used to distinguish between the different categories of moves considered by the revised formula that examines the likelihood of co-occurrence between moves. Since both moves co-occur at the same time, the revised formula is shown below:

$L\left(M_{c_{i} t} \& M_{c_{j} t}\right)=\frac{\operatorname{Pr}\left(M_{c_{j} t} \mid M_{c_{i} t}\right)-\operatorname{Pr}\left(M_{c_{j} t}\right)}{1-\operatorname{Pr}\left(M_{c_{j} t}\right)}$

In Eq. (2), the likelihood metric compares the conditional probability of both codes co-occurring, as determined by $\operatorname{Pr}\left(M c_{j}\right) \mid-$ $\operatorname{Pr}\left(M c_{i}\right)$, to the expected degree of association, assuming that both are independent, as in $\operatorname{Pr}\left(M c_{j}\right)$. The numerator of this formula thus equals the degree of co-occurrence between distinct categories of codes at the same time minus the degree of co-occurrence expected under independence. In our data $M c_{j}$ can be defined as a planning code from metacognition and $M c_{i}$ a change code from co-regulation. A positive value on the numerator signifies that the observed degree of co-occurrence is higher than expected under independence, while a negative value means that the observed co-occurrence is less than that expected under independence. A numerator value equal to zero means that there is no co-occurrence between both code categories. As such, the size and magnitude of $L$ reflects the direction and magnitude of the co-occurrence between $M c_{i}$ and $M c_{j}$, while taking into account the rate of $M c_{i}$ throughout the PBL session.

The second stage of the proposed data mining technique involves representing the significant relationships between tutorial dialogue moves in the form of a heat map visualization (Wilkinson \& Friendly, 2009). Heat maps have been used to illustrate the frequency of intra-relationships amongst metacognitive activities across different time periods and groups of students, assigning different colors to indicate the lowest and highest occurrences (Kinnebrew, Segedy, \& Biswas, 2014). The heat map visualizations outlined in this paper draws attention to areas where two distinct types of dialogue moves are more likely to occur at the same time throughout the tutoring session. The differences in shades and colors are a function of the likelihood of co-occurrence between any two distinct types of tutorial moves. This visual representation of the inter-relationship amongst dialogue moves provides a deeper understanding of the impact of co-regulatory episodes during the tutorial session towards group members' self-regulatory activities. Alternatively, the different aspects of self-regulatory activities (i.e., metacognitive and affective) occurring at the level of individuals within a group can also be depicted as a heat map. 


\section{Results}

\subsection{Is there evidence of metacognitive activity change over the} duration of the PBL?

The frequencies of orientation, planning, executing, monitoring evaluation, and elaboration activities were calculated, as well as the sum of all turns demonstrating one or more types of metacognitive activity. Frequencies were then converted into percentages for ease of comparison. To calculate percent of overall metacognitive activity, we summed the total number of turns coded and divided by the total number of turns in the transcript. To calculate percent of different metacognitive activity types, we divided the sum of each type by the total number of codes for each transcript and we analyzed these differences over time (session 1 and 2 of the PBL activity). A chi square analysis was conducted and there was a significant difference in the count of metacognitive activities and the days of the PBL session, $\chi^{2}(6, N=517)=14.14, p=.03$.

Generally, the second session revealed more metacognitive activities overall than the first session (see Table 4). The increase in the group discourse may be an indicator that the group was improving in their metacognitive activities pertaining to the task at hand. Planning occurred the most frequently in both sessions (23\% and $22 \%$, respectively) since group members discussed how they would go about giving bad news in the context of future situations. Although orientation was an important focus of the first session (18\%), the second session put more emphasis on how to execute the plan to deliver bad news (18\%). This trend is to be expected in groups that are functioning well in that they must learn the task rules prior to executing actions.

Table 4 demonstrate the dynamic unfolding of metacognitive activities over the first half and second half for each session, revealing the fluid nature of these constructs that change as the group evolves in sharing and understanding of the task. Overall, more metacognitive activities were noticeable during the second PBL session, however the patterns varied between and across sessions. For this reason we divided the activities into first half (0-50\%) and last half (from $50 \%$ to $100 \%$ ) activities. Qualitative excerpts reveal the nature of these shifts in metacognitive activities over time. The group is active in session one displaying systematic and reflective discussions. Metacognitive processes occurred in more sequential orders, as orientation and planning were frequently noticeable at the beginning of the session. As the discussion advanced, we noticed more monitoring, evaluation, and elaborating. To exemplify this shift we provide an example of the discourse at the beginning and end of the day 1 session. The coded dialogue moves are inserted at the end of each line of the transcript.

At the beginning of day 1 of the PBL the metacognitive activities were more frequently about orientation and planning:
CF: ok so, if you look at ...we are going to look at we what we write as facts, ideas, or learning issues. [Orientation]

CF: how would as a group, how would you classify what HK2 has written down? [Orientation]

C1: they're ideas? [Planning]

CF: what would you think HK1, C2? [Orientation]

HK1: could also be facts depending on how uh... [Planning]

At the end of the day 1 PBL the metacognitive activities were more evaluative and elaborative:

C2: um, okay so, any other events that you want to discuss? Like for example I notice that um the doctor was offering a lot of support to the patient um, you know at many times during the interview she was offering uh you know to see a male doctor, to bring in the spouse to follow up, how do you think that $\mathrm{uh}$, the patient react, do you think this is a good approach to you? Telling him and showing him the support? [Monitoring] C1: I uh I think it was a good way of offering uh offering for example speaks of a male physician if he would be more comfortable with that, and she did in a way she didn't sound like he was trying, like she was trying to, like get away from the situation and off loaded onto someone else's. [Evaluating]

C1: She didn't wanna deal with it, which is like a possible thing that can come up right? You are asking someone if they would see someone else then they might think, well why don't you um see me? Then they're like, am I bad patient is like that kind of a thing, and I think she handled that well. [Elaborating]

By the second PBL session, the patterns of discourse were less rigid since the ground rules had been established in day 1 . The second session demonstrated more movement back and forth across regulatory activities. Students started the discussion in a more active and organized way and participated in inputting ideas and were able to focus on assigned task demands. For example:

HK1: After review "SPIKES" it sort of snaps it into a rigid yet confident process which we can refer to. And I think really places a lot the ideas thrown out yesterday into perspective. [Evaluation]

HKF: So you think it helps a lot. [Orientation]

HK1: yeah to a certain extend it helps to organize the thoughts. [Elaborating]

HKF: um, what about $\mathrm{C} 1$ ?... Is it the first time you hear about "SPIKES" model? [Planning]

The Hong Kong facilitator and the group leader structured their discussion per topics, tasks, or goals. Performance and self-reflection stages of metacognitive activities were frequently noticed.

Table 4

Metacognitive activities over time in PBL on day $1 \& 2$

\begin{tabular}{|c|c|c|c|c|c|c|c|c|c|c|}
\hline \multirow[t]{3}{*}{ Metacognitive activities } & \multicolumn{5}{|c|}{ Elapsed time in day 1} & \multicolumn{5}{|c|}{ Elapsed time in day 2} \\
\hline & \multicolumn{2}{|c|}{ Frequency } & \multicolumn{3}{|c|}{ Percentage } & \multicolumn{2}{|c|}{ Frequency } & \multicolumn{3}{|c|}{ Percentage } \\
\hline & 1st Half & 2nd Half & 1st Half & 2nd Half & Total & 1st Half & 2nd Half & 1st Half & 2nd Half & Total \\
\hline Orientation & 22 & 7 & 0.14 & 0.04 & 0.18 & 22 & 12 & 0.06 & 0.03 & 0.09 \\
\hline Planning & 36 & 1 & 0.22 & 0.01 & 0.23 & 53 & 26 & 0.15 & 0.07 & 0.22 \\
\hline Executing & 13 & 7 & 0.08 & 0.04 & 0.12 & 34 & 28 & 0.10 & 0.08 & 0.18 \\
\hline Monitoring & 1 & 8 & 0.01 & 0.05 & 0.06 & 14 & 19 & 0.04 & 0.05 & 0.09 \\
\hline Evaluation & 0 & 21 & 0.00 & 0.13 & 0.13 & 15 & 38 & 0.04 & 0.11 & 0.15 \\
\hline Elaboration & 0 & 20 & 0.00 & 0.12 & 0.12 & 10 & 16 & 0.03 & 0.05 & 0.08 \\
\hline No code & 20 & 6 & 0.12 & 0.04 & 0.16 & 47 & 21 & 0.13 & 0.06 & 0.19 \\
\hline Total & 92 & 70 & 0.57 & 0.43 & 1.00 & 195 & 160 & 0.55 & 0.45 & 1.00 \\
\hline
\end{tabular}


Students tend to perform one full loop of metacognitive activities in small sections that lead to shared-metacognitive co-regulatory activities.

The qualitative data revealed that the early discussions in session 1 demonstrated forethought and performance phases consisting of planning, monitoring, and executing. As learners approach the latter half of the session, they tended to be more reflective, where activities of monitoring, evaluating, and elaborating encouraged a common understanding of the subject. By day 2 less time was spent on forethought activities in the dialogue and more on the co-occurrences of metacognitive processes.

We explore the nature of co-regulatory activities below.

\subsection{Does the nature of co-regulatory activities change over time?}

Co-regulation was examined at the episode level over time. The frequency data provides strong evidence of co-regulatory activities in both sessions, but the chi-square analysis revealed no significant relationship between the frequencies of co-regulatory episodes and the days of the PBL session, $\chi^{2}(4, N=63)=3.49, p=.48$. Both sessions revealed similar counts of co-regulatory activity. However, some differences existed in the patterns of data.

In particular, the co-regulatory codes (activate and confirm), which are activities that are valenced positively, were high in both sessions with an increase over time. Members contributed more ideas in line with previous directions indicating a more cohesive group. Each student's turn was longer and thus resulted in longer episodes in session 2. Actions that were less cohesive, such as "change" (changing the direction of the discourse) tended to decrease over time.

The qualitative data indicate that the medical facilitator or designated group leader spent a large amount of time facilitating the PBL in session 1 and initiating the co-regulatory episode (as expected). For instance, $\mathrm{C} 2$, the student facilitator questioned the others on the sub topic of preparing the setting before breaking bad news to patients. The students then contributed their ideas, one by one. The facilitator often introduced a new problem or concept that needed to be considered, which frequently led to a change in direction. However, the change was not necessarily due to incorrect activities on the students' part but rather due to the facilitator instigating a new direction that was followed by an "activate" code. From the example, C2 (the group leader) tried to shift the discussion toward another issue where the episode involved following turns from $\mathrm{C} 2-\mathrm{C} 1-\mathrm{HK} 1$, then $\mathrm{C} 2$ confirmed the previous discussion and started a new macro co-regulatory episode of a "confirm" code. The co-regulatory activities need to be examined in context to understand how meaning making occurs.

C1: And of course we have to note the emotion and the condition of the patient. [Activate]

HK1: Say if the patient enters in the consultation room, and she is very depressed, so may be at that time, it may not very be appropriate for us to break the new at that moment. [Activate] C2: Ok so then once you have right setting and know the emotion of the condition of the patient then what would you do. What kind of thing that you would have to start to say? [Change]

C1: I think it would be good before getting straight to the bad news, you ask any question that you might need to ask, like new symptoms or complaints or anything, because once given any bad news then it would be very difficult after that point to ask them relevant questions or gather information that you might need. [Change]

HK1: also perhaps, ask the patient what her expectation of the consultation is. [Change]

C2: Yeah, it makes a lot of sense. [Confirm]
C2: I think I would also ask the patient what their concerns are, or depends on the test that you would've of done, of course. But uh in most cases I think it is something or information you cannot get after you gave the bad news. [Confirm]

The highest co-occurrences of co-regulatory episodes were active, confirm, and change. Although the change code usually has a negative valence, in this context, it can be promoting understanding or monitoring by providing a new clue or idea that can branch from the current discourse. In summary, these high co-regulatory episodes were promoting on-going discussions leading to better collective knowledge construction (see Table 5).

\subsection{What is the nature and frequency of social-emotional interactions over the duration of the PBL (from day 1 to day 2)?}

Although social emotional interactions were prevalent in both sessions (67.5\% and $79.6 \%$ respectively), there were no significant differences in the frequency of interactions between days of the PBL, $\chi^{2}(4, N=517)=4.10, p=.39$. However, Table 6 indicates that the most frequent interactions pertained to the Interactive Social Presence category, which consisted of subcodes (i.e. continuing a thread, asking questions, giving information) expressing appreciation of other comments and encouraging contributions.

An example was provided below of the Canadian student facilitator encouraging the participation of another group member:

C2: So what do you mean on knowing the emotion could you expand that a little bit? [Asking Questions]

HK1: say if the patient enters in the consultation room, and she is very depressed, so may be at that time, it may not very be appropriate for us to break the new at that moment. [Providing Further Information]

$\mathrm{C} 2$ : Ok so then once you have right setting and know the emotion of the condition of the patient then what would you. . what kind of thing that you would have to start to say? [Asking Questions]

C1: I think it would be good before getting straight to the bad news, you ask any question that you might need to ask, like new symptoms or complaints or anything, because once given any bad news then it would be very difficult after that point to ask them relevant questions or gather information that you might need. [Continuing a Thread]

This illustrates the cohesion between the group interactions where everyone contributes to a shared understanding of the task at hand. Recent research on the role of student group cohesiveness and interaction on team effectiveness in online graduate management education suggests a strong relationship between social presence and learning outcomes (Arbaugh, 2005; Hwang \& Arbaugh, 2006; Williams, Duray, \& Reddy, 2006; Yoo, Kanawattanachai, \& Citurs, 2002). This emerging research stream implies that activities that cultivate social presence also enhance the learner's engagement within the learning session. Collaborative activities provide learners greater opportunities to increase social presence and a greater sense of online community, which can also lead to an improved socio-emotional climate in the PBL session (Richardson \& Swan, 2003; Rovai, 2002) yielding to advanced social emotion regulation.

3.4. What is the relationship between metacognition, co-regulation, and social-emotional interactions as identified in the PBL activities?

\subsubsection{Mining for inter-relationships between regulatory behaviors}

The first stage of the analysis aims to identify common patterns in co-occurrences between distinct types of dialogue moves found 
Table 5

Co-regulatory activities over time in PBL on day $1 \& 2$.

\begin{tabular}{|c|c|c|c|c|c|c|c|c|c|c|}
\hline \multirow[t]{3}{*}{ Co-regulatory activities } & \multicolumn{5}{|c|}{ Elapsed time in day 1} & \multicolumn{5}{|c|}{ Elapsed time in day 2} \\
\hline & \multicolumn{2}{|c|}{ Frequency } & \multicolumn{3}{|c|}{ Percentage } & \multicolumn{2}{|c|}{ Frequency } & \multicolumn{3}{|c|}{ Percentage } \\
\hline & 1st Half & 2nd Half & 1st Half & 2nd Half & Total & 1st Half & 2nd Half & 1st Half & 2nd Half & Total \\
\hline Activate & 2 & 5 & 0.09 & 0.24 & 0.33 & 9 & 8 & 0.21 & 0.19 & 0.40 \\
\hline Confirm & 4 & 1 & 0.19 & 0.05 & 0.24 & 4 & 6 & 0.10 & 0.14 & 0.24 \\
\hline Slow & 0 & 0 & 0.00 & 0.00 & 0.00 & 2 & 2 & 0.05 & 0.05 & 0.10 \\
\hline Change & 3 & 4 & 0.14 & 0.19 & 0.33 & 3 & 5 & 0.07 & 0.12 & 0.19 \\
\hline No code & 2 & 0 & 0.10 & 0.00 & 0.10 & 3 & 0 & 0.07 & 0.00 & 0.07 \\
\hline Total & 11 & 10 & 0.52 & 0.48 & 1.00 & 21 & 21 & 0.50 & 0.50 & 1.00 \\
\hline
\end{tabular}

Table 6

Social emotional interactions over time in PBL on day $1 \& 2$.

\begin{tabular}{|c|c|c|c|c|c|c|c|c|c|c|}
\hline \multirow[t]{3}{*}{ Social emotion interactions } & \multicolumn{5}{|c|}{ Elapsed time in day 1} & \multicolumn{5}{|c|}{ Elapsed time in day 2} \\
\hline & \multicolumn{2}{|c|}{ Frequency } & \multicolumn{3}{|c|}{ Percentage } & \multicolumn{2}{|c|}{ Frequency } & \multicolumn{3}{|c|}{ Percentage } \\
\hline & 1st Half & 2nd Half & 1st Half & 2nd Half & Total & 1st Half & 2nd Half & 1st Half & 2nd Half & $\overline{\text { Total }}$ \\
\hline ASP & 5 & 8 & 0.03 & 0.05 & 0.08 & 11 & 15 & 0.03 & 0.04 & 0.07 \\
\hline ISP & 73 & 53 & 0.45 & 0.33 & 0.78 & 157 & 138 & 0.44 & 0.44 & 0.83 \\
\hline CSP & 3 & 2 & 0.02 & 0.01 & 0.03 & 6 & 3 & 0.02 & 0.02 & 0.03 \\
\hline $\mathrm{NI}$ & 2 & 0 & 0.01 & 0.00 & 0.01 & 3 & 3 & 0.01 & 0.01 & 0.02 \\
\hline No Code & 9 & 7 & 0.06 & 0.04 & 0.10 & 18 & 1 & 0.05 & 0.05 & 0.05 \\
\hline Total & 92 & 70 & 0.57 & 0.43 & 1.00 & 21 & 21 & 0.55 & 0.45 & 1.00 \\
\hline
\end{tabular}

in the coded transcript that occurred between group members in the PBL session. The discourse corpus was examined as a whole by collapsing both PBL sessions. Eq. (2) was applied to the coded transcript of the discourse by analyzing the group discussion at a finer grain-size, consisting of the dialogue moves that are indicative of self-regulatory behaviors at the level of each individual group member. The same equation was applied to investigate the occurrence of these self-regulatory behaviors within broader episodes that occurred within the discussion, which were indicative of specific types of co-regulatory behaviors that occurred at the group level. The frequency count data of each regulatory behavior and their co-occurrence with other behaviors is shown in Tables 79. The application of the data mining technique to the frequency count data and the resulting likelihood metric ranks, joint probabilities, and conditional probabilities are shown in Table 10.

As an example, the joint probability, denoted by $\operatorname{Pr}\left(M c_{j} \cap M c_{i}\right)$, gives the probability that each behavior in the coded transcript falls in the same time period within the thread of discussion. For instance, there were a total of 52 instances where an individual engaged in planning, while the group discussion shifted to a new idea or construct in line with the previous thread of discussion. Given that the collapsed transcript included a total of 532 dialogue moves, the probability of both regulatory behaviors co-occurring is equal to 0.10 . In contrast, the conditional probability, referred to as $\operatorname{Pr}\left(M c_{j} \mid M c_{i}\right)$, gives the probability that one behavior occurred in the coded transcript at the same time period as another within the thread of discussion. Given that the same transcript featured a total of 217 dialogue episodes that were coded as activating a new idea or construct, the probability of an individual planning within this type of co-regulatory episode is equal to 0.24 . The likelihood metric is simply calculated as the ratio between the conditional probability of both these behaviors co-occurring and the probability of planning occurring within the coded transcript. Since there were 63 instances of planning behaviors within the coded transcript, which equaled a probability of 0.12 , the likelihood metric associated to the co-occurrence of activate and planning equals 0.14. The co-occurrence between these two regulatory behaviors was ranked as the highest positive value with respect to all co-regulatory episodes and metacognitive activities.
Table 7

The frequency count data of co-occurrences between co-regulatory episodes and metacognitive activities.

\begin{tabular}{lrrrrrr}
\hline \multirow{2}{*}{ Co-regulatory episodes } & \multicolumn{7}{c}{ Metacognitive activities } \\
\cline { 2 - 7 } & \multicolumn{1}{c}{ OR } & \multicolumn{1}{c}{ PL } & EX & MO & EV & EL \\
\hline Activate & 31 & 52 & 26 & 22 & 40 & 19 \\
Confirm & 16 & 29 & 25 & 8 & 19 & 7 \\
Slow & 1 & 4 & 5 & 5 & 1 & 3 \\
Change & 10 & 17 & 15 & 7 & 14 & 17 \\
\hline
\end{tabular}

Note. Orientation (OR); planning (PL); executing (EX); monitoring (MO); evaluation (EV); elaboration (EL). Other codes are not included in this table.

Table 8

The frequency count data of co-occurrences between co-regulatory episodes and socio-emotional interactions.

\begin{tabular}{lcccc}
\hline \multirow{2}{*}{ Co-regulatory episodes } & \multicolumn{5}{l}{ Socio-emotional interactions } \\
\cline { 2 - 5 } & ASP & ISP & CSP & NSE \\
\hline Activate & 16 & 177 & 4 & 5 \\
Confirm & 3 & 103 & 3 & 2 \\
Slow & 5 & 18 & 2 & 0 \\
Change & 8 & 76 & 1 & 0 \\
\hline
\end{tabular}

Note. Activating Social Presence (ASP); Interactive Social Presence (ISP); Cohesive Social Presence (CSP); Negative Social-Emotional Interaction (NSE). Other codes are not included in this table.

One of the main considerations in utilizing sequential pattern mining to uncover common patterns is the stability of the trends that are identified across different PBL sessions. Do the ranked probabilities of co-occurrences between discourse moves change throughout PBL sessions? Are the most likely co-occurring behaviors the same, irrespective of the students and facilitators in a session? These questions are particularly important for drawing generalizable conclusions regarding the inter-relationships amongst constructs in theories of co-regulation. In this particular dataset, a chi-square test on the frequency count data for each type of regulatory behavior suggests that there was a significant difference between the occurrences of metacognitive activities across 
Table 9

The frequency count data of co-occurrences between metacognitive activities and socio-emotional interactions.

\begin{tabular}{lccll}
\hline \multirow{2}{*}{ Metacognitive activities } & \multicolumn{4}{c}{ Socio-emotional interactions } \\
\cline { 2 - 5 } & ASP & ISP & CSP & NSE \\
\hline Orientation & 3 & 53 & 1 & 2 \\
Planning & 4 & 99 & 3 & 1 \\
Executing & 10 & 68 & 0 & 3 \\
Monitoring & 4 & 31 & 2 & 2 \\
Evaluation & 2 & 68 & 1 & 0 \\
Elaborating & 4 & 36 & 2 & 0
\end{tabular}

Note. Activating Social Presence (ASP); Interactive Social Presence (ISP); Cohesive Social Presence (CSP); Negative Social-Emotional Interaction (NSE). Other codes are not included in this table.

Table 10

The ranked probabilities of most likely co-occurrences between tutorial discourse moves.

\begin{tabular}{lcll}
\hline$L\left(M c_{i}\right.$ \& $\left.M c_{j}\right)$ & Rank & $\operatorname{Pr}\left(M c_{j} \cap M c_{i}\right)$ & $\operatorname{Pr}\left(M c_{j} \mid M c_{i}\right)$ \\
\hline Co-regulatory episodes $\mathcal{E}$ metacognitive & activities & & \\
Activate \& planning & 1 & 0.10 & 0.24 \\
Change \& planning & 2 & 0.03 & 0.18 \\
Change \& elaboration & 3 & 0.03 & 0.18 \\
Co-regulatory episodes E socio-emotional interactions & \\
Activate \& interactive social presence & 1 & 0.33 & 0.82 \\
Change \& interactive social presence & 2 & 0.14 & 0.81 \\
Slow \& interactive social presence & 3 & 0.03 & 0.64 \\
Metacognitive activities \& socio-emotional interactions & \\
Evaluation \& interactive social presence & 1 & 0.13 & 0.92 \\
Planning \& interactive social presence & 2 & 0.19 & 0.85 \\
Orientation \& interactive social presence & 3 & 0.10 & 0.84 \\
\hline
\end{tabular}

sessions $\left(\chi^{2}(6, N=517)=14.14, p=.03\right)$, but no other differences were found in terms of co-regulatory episodes and socio-emotional interactions $\left(\chi^{2}(4, N=63)=3.49, p=.48 ; \chi^{2}(4, N=517)=4.10\right.$, $p=.39$, respectively). We then analyzed the frequency count of metacognitive activities as they occurred in ten bins, each one corresponding to ten percent of the elapsed time of a particular session. The resulting trend confirmed an increase in metacognitive activities during the second session in comparison to the first one. In the first session, metacognitive activities occurred as series of events, as orientation and planning were frequently noticeable at the beginning of the session. Then as the discussion advanced, we noticed more monitoring, evaluation, and elaborating. This pattern was less evident in the second session, as the medical facilitator addressed issues from the previous session by jumping back and forth across these regulatory phases.

To formulate generalizable claims, it is noteworthy to mention that the significance of each likelihood metric can be tested across multiple tutorial sessions using resampling methods to calculate one sample t-tests, as shown in the method outlined by D'Mello et al. (2010). For the purposes of interpreting the two combined sessions examined in this study, we limit our interpretation of the likelihood metrics to patterns in the data that can be used to generate testable hypotheses in future studies. Although the results obtained are not sufficient to warrant generalizable claims, we interpret the most common patterns by drawing on excerpts from the coded transcript. Furthermore, we demonstrate the use of heat map visualizations to facilitate the interpretation of these patterns.

\subsubsection{Representing inter-relationships between regulatory behaviors}

The second stage of our analysis entails the representation of each combination of co-occurrences between distinct types of dialogue moves as a heat map visualization. The heat map assigns a red color to the co-occurrences that are the most likely to occur and a blue color to the ones that are least likely to occur. The baseline color is white for inter-relationships with no apparent directionality. The color gradient is determined on the basis of whether the value is above or below the 1st Half percentile of the likelihood metric distribution. In doing so, the heat map allows researchers to grasp the relative importance of co-occurring regulatory behaviors at specific levels of granularity (i.e. co-regulatory episodes and metacognitive activities). These heat maps are derived from the analysis summarized in Table 10. Figs. 3-5 illustrate the relative importance of co-occurring regulatory behaviors at both the individual and group level within the coded transcript for the combined PBL sessions.

As can be seen from the heat maps, the likelihood of co-occurring regulatory behaviors at the individual and group levels provide important insights into building a theoretical model for the processes that occurred during the PBL session. At the level of the group discourse, it is apparent from the heat maps that episodes of discussion that were characterized by activating a new idea or construct in line with the previous thread of discussion, in addition to changing topics completely, had the most impact towards self-regulatory behaviors of individual group members. During these critical moments, individual group members were more likely to formulate plans, elaborate on a particular topic of discussion, as well as engage in interactive activities such as encouraging contributions, expressing agreements, and asking questions. At the level of the individual group members, the selfregulatory behaviors that co-occurred during the session are more evident, as instances of evaluating or being critical were more likely to occur while the group atmosphere encouraged contributions.

To exemplify a common co-regulatory process that was likely to occur during the PBL session, this excerpt from the corpus illustrates individual group members' efforts to formulate a plan while a new idea was proposed in the discussion thread. The coded dialogue moves are inserted at the end of each line of the transcript:

CF: So uh my question to the group then (C2), I will have you run the discussion is how would you organize the things you would do chronologically with the patient. When you are about to give a bad news [Activate $\mathcal{E}$ Planning]

C2: um you want me to classify the points that... [Activate $\mathcal{E}$ Orientation]

CF: No you would help the group to classify [Activate $\mathcal{E}$ Orientation]

C2: Okay, um, so group how would you classify those points? [Activate E Planning]

In this excerpt, the Canadian medical facilitator asks a question to the other group members. In doing so, the facilitator prompts

\begin{tabular}{l|llllll} 
& \multicolumn{5}{c}{ Metacognitive Activities } \\
\cline { 2 - 6 } Co-Regulatory Episodes & OR & PL & EX & MO & EV & EL \\
\hline Activate & & & & & & \\
Confirm & & & & & & \\
Slow & & & & & & \\
Change & & & & & & \\
\hline
\end{tabular}

Fig. 3. Heat map of co-occurrences between co-regulatory episodes and metacognitive activities. Notes: orientation (OR); planning (PL); executing (EX); monitoring (MO); evaluation (EV); elaboration (EL). 
Socio-Emotional Interactions

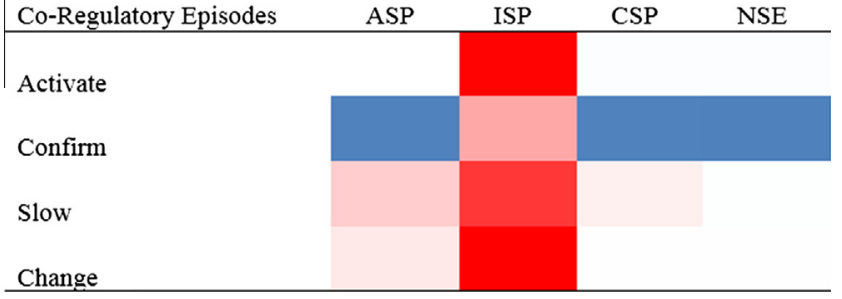

Fig. 4. Heat map of co-occurrences between co-regulatory episodes and socioemotional interactions. Notes: Activating Social Presence (ASP); Interactive Social Presence (ISP); Cohesive Social Presence (CSP); Negative Social-Emotional Interaction (NSE).

\begin{tabular}{lllll}
\hline & \multicolumn{3}{c}{ Socio-Emotional Interactions } \\
\cline { 2 - 4 } Metacognitive Activities & ASP & ISP & CSP & NSE \\
\hline Orientation & & & \\
Planning & & \\
Executing & \\
Monitoring & \\
Evaluation & \\
Elaborating
\end{tabular}

Fig. 5. Heat map of co-occurrences between metacognitive activities and socioemotional interactions. Notes: Activating Social Presence (ASP); Interactive Social Presence (ISP); Cohesive Social Presence (CSP); Negative Social-Emotional Interaction (NSE).

group members to classify the points that need to be addressed in chronological order when delivering bad news to patients. In doing so, individual group members are encouraged to formulate the best plan of action when dealing with this type of situation. One of the main implications of this finding is that when the topic of the group discussion shifts, group facilitators should be trained in evaluating the quality of the plans formulated by contributing members.

In terms of engaging in interactive activities while a new idea is proposed in the thread of discussion, the following excerpt illustrates a constructive contribution from an individual group member. A Hong Kong (HK1) student makes this contribution in response to a comment made by one of the Canadian students (C2):

C2: sorry I am not sure I understand what I am supposed to do [Activate \& Affective Social Presence]

HK1: we can firstly analyze it through the three different phases um toward breaking the bad news or even before, so I propose there might be a phase for pre-consultation, so anything before prior to seeing the patient, and then the actual consultation phase and that's when you actually see the patient and deliver the bad news; there is a post consultation phase, anything that takes place after the patient has left, so maybe follow ups, and then through each phase you can then further dissect it into um different sectors or divisions where you can then pass by or expand on it. For example, consultation you can then analyze it as an icebreaking moment and then follow by a rapport building, something like that. [Activate $\mathcal{E}$ Interactive Social Presence]

In this excerpt, the Canadian student was unsure about the steps involved in delivering bad news to a patient. In response, the Hong Kong student contributed to the thread by proposing a basic distinction, the pre-, actual- and post-consultation phase. This contribution is an example of an appropriate co-regulatory episode wherein the socio-emotional interactions that occur are aligned in a coherent manner. The first students' need for help was met by the second students' comment, as the latter conveyed attention to the other member and responded accordingly. Episodes of discussion where a new topic logically unfolds from the previous thread of discussion may be more conducive to or might necessitate further instances of Interactive Social Presence.

In regards to self-regulatory processes in the group discussion, and the co-occurrences of metacognitive activities and socio-emotional interactions, the heat map indicates an inter-relationship between evaluative comments and positive contributions to the thread of discussion. In the following excerpt, the group facilitator shifts roles with one of the Canadian students:

[CF] so um good point ( $\mathrm{C} 1)$, so you uh said that when a patient is silent like that uh chances are the patient uh may not be able to hear any other information. And perhaps the right thing to do is to stop and ask the patient what they are thinking or how they feel [Elaborating \& Interactive Social Presence]

[CF] anything else? So C1 I will give the floor back to you. [Evaluating \& Interactive Social Presence]

[C1] so um, okay so, any other events that you want to discuss? Like for example I notice that um the doctor was offering a lot of support to the patient um, you know at many times during the interview she was offering uh you know to see a male doctor, to bring in the spouse to follow up, how do you think that uh, the patient react, do you think this is a good approach to you? Telling him and showing him support? [Monitoring $\mathcal{E}$ Interactive Social Presence]

The medical facilitator first prompts individual group members to evaluate the previous comment in the thread of discussion. At the same time, the facilitator attempts to encourage the sustained involvement from other group members by allowing the student to lead the discussion. Constructive contributions from individual group members that are critical in nature are seen here as dependent upon a positive climate for discussion. Although this excerpt illustrates that group members may not always respond to such prompts, it conveys the importance of considering both the affective and metacognitive aspects of self-regulation, and how one mediates the other. Interventions aimed at facilitating evaluative comments should take into consideration the overall climate of the discussion and the capabilities of facilitators to engage in Interactive Social Presence.

\section{Discussion}

Self-regulated learning is an essential ingredient to becoming competent in any domain. Experts in all domains perform higher then novices on assessments of metacognition (Chi, Glaser, \& Farr, 1988). Experts know what they know and do not know in their respective fields. Similarly, competent physicians develop important self-regulatory skills needed in their specializations. This paper explores how medical students learn to regulate their learning about how to give bad news to patients. Even seasoned physicians struggle in their confidence about their ability to communicate such news effectively (Sise, Sise, Sack, \& Goerhing, 
2006). The physician must regulate their emotions as well as that of their patients. Medical students have even more difficulty with this task since they have very little experience.

The research reported in this paper presents a unique computer-supported international PBL environment designed to facilitate learning about how to communicate bad news to patients. The computer environment was created to allow for synchronous communication between students and medical facilitators who are working at a distance to learn about the issues involved in communicating bad news. The curriculum and learning objectives involved two medical cases that were used to trigger group dialogue about the medical interview. The medical facilitators' use a guiding medical algorithm, SPIKES, that situates relevant issues to attend to during a medical interview. The SPIKES algorithm is used to monitor and facilitate medical students as they learn how best to communicate these difficult matters. Two videos, one from Canada and one from Hong Kong, were used to trigger the group discourse about how to communicate positive HIV test results to patients. Since PBL environments involve small groups, it was important to explore both the individual metacognitive processes involved in learning, as well as the co-regulatory processes that affected the group discourse and the social-emotional interactions that promote or hinder learning in this PBL.

Our analysis provided an in-depth look at the types of metacognitive and co-regulatory activities that this PBL situation affords. Social-emotional interactions were examined as well since these were a key aspect of co-regulation leading to a shared understanding of the problem space. Furthermore, we examined the frequency and associations between metacognitive, co-regulation and social emotional activities to understand the complexities of these interactions. The theoretical and methodological insights are discussed below with a summary of the findings.

\subsection{Theoretical impact}

We provide operational definitions of metacognition, self-regulation, co-regulation and identify the role of social emotional processes in such contexts. These definitions are used to situate our work. Volet et al. (2013) state that individuals use cognitive and metacognitive regulatory processes to plan, perform and maintain desired objectives. Whereas co-regulation directly involves social aspects where group members ease cognitive demands by sharing metacognitive demands. Lajoie and Lu (2012) found that technology can support this type of co-regulation and lead to productive learner outcomes in terms of faster arrival at a mutual understanding and faster actions toward patient management.

A major consideration for researchers who are trying to position themselves along the self-to co- to socially shared regulation is the context of the problem solving activity itself. In other words, what is the nature of the problem that individuals are asked to solve. Does the problem lend itself more to individual problem solving or group problem-solving? If the group is solving a task oriented problem where everyone works together to ease the cognitive demands by sharing the metacognitive demands of monitoring, evaluating and regulating task processes then they are co-regulating. However, if a group task is truly shared and cannot be done unless collaborative interactions occur as a whole, they are participating in shared regulation (see Hadwin \& Oshige, 2011). In analyzing the PBL activity we determined that our problem was one of co-regulation rather then shared regulation since medical students were monitoring and evaluation each other, building and elaborating on ideas that they would need to implement in their own practice.

A socially shared regulation in medicine would require everyone working together as a whole to save the patient's life. For example, tasks would need to be distributed and shared where an understanding of others roles would be needed. Trauma teams for instance, spend time establishing a team mental model, where the knowledge structure is shared across team members, allowing them to share a similar understanding of the task (Cruz-Panesso, Lajoie, \& Lachapelle, 2013). Accurate knowledge structures that are shared across team members allow them to communicate implicitly as well as to make similar inferences and predictions.

Our recommendations to researchers are to first identify the task objective of the problem solving task that the group has embraced, and then select the theoretical assumptions that best fit the situation. Once these assumptions are met, then methodological goals can be met that fit the parameters of the task.

\subsection{Methodological insights}

We selected and operationalized constructs of metacognitive, co-regulatory and social-emotional activities that are specific to the task of learning how to give bad news to patients. Code-books were established for each metric based on theoretical assumptions that were applied in this particular context. We then looked at the co-occurrences of these regulatory activities.

The research metrics used in this study document the temporal nature of how regulatory processes change over time as the group works together. These metrics can be replicated to indicate the extensiveness of regulatory activities on other tasks. Data mining techniques can help provide evidence of how regulation is supported by co-occurring activities. We call on researchers to utilize the statistical testing approach utilized by D'Mello et al. (2010) to identify co-occurring regulatory behaviors that are found statistically significant across multiple learning sessions. Alternatively, we recommend evaluating alternative methods to identify interesting patterns, such as capturing regulatory behaviors with rare or isolated co-occurrences across sessions. Examining such cooccurrences is a first step in understanding where instruction and scaffolding may be needed to improve a particular learning situation.

\subsection{Summary of findings}

The PBL group worked together reviewing patient cases over a two-day period with the goal of determining the best way to communicate bad news. The goal of the intervention was for medical students to determine which strategies were most effective for giving bad news and to make adaptive adjustments in their understanding based on continuous metacognitive monitoring. In considering effective strategies they reviewed the SPIKES protocol and analyzed video cases to see how physicians addressed the relevant components of the medical interview. Another learning issue in these PBL sessions was a group reflection was on how the context and culture influenced the type of communication strategies. During the course of learning, the medical student may select strategies and assess whether these particular strategies are effective in meeting previously set learning subgoals. The student may also evaluate the emerging understanding of the topic and make the necessary adjustments regarding knowledge, behavior, effort, and other aspects of the learning context. The co-construction of knowledge was reflected in the co-regulatory episodes and demonstrated the type of strategies and learning issues that were seen as key to the case in question. The adaptive adjustments in the PBL groups thinking was based on continuous metacognitive monitoring and control related to the standards for the particular learning task that can be seen to facilitate decisions regarding when, how, and what to regulate (Azevedo et al., 2010).

Although planning was the most predominant activity throughout the two sessions, the discussion unfolded first in accordance with the basic stages of individual regulation, spanning from 
forethought, execution, to self-reflection. By the second session learners were more adaptive, as the discussion addressed specific topics within each phase in a non-linear fashion. These changes are important since it shows growth and progression on the group's part. The qualitative data reveal that forethought and performance phases such as planning, monitoring, and executing are followed by more reflective phases by the second session where activities of monitoring, evaluating, and elaborating encourage a common understanding of the significant elements of breaking bad news.

Co-regulation is more than a summation of metacognitive activities demonstrated by each individual in a group. For this reason we looked at the episodes in the group discourse that activated shared understanding or inhibited it. High percentages of co-regulation were identified on both days, where one day was not better than another in terms of such activity. The discourse revealed high levels of positive activation toward moving the discourse forward. When the discussion took a change in direction it was usually because a medical facilitator was introducing new topics rather than correcting a student's assumptions.

Our assumptions were that there were different types of social emotional interactions that would lead to a healthy or productive community of inquiry. For this reason we examined the types of cohesion (active, cohesive, interactive, and negative) in the discourse. There was a consistent demonstration of Interactive Social Presence that helped the group attend to the goals of the PBL over both sessions. Interactive Social Presence in the group discourse was best exemplified by encouraging contributions from others, giving information, etc. This type of positive interaction led to a well-managed PBL that led to a high level of cohesion about what to do next.

Finally, we explored how metacognitive, co-regulatory and social-emotional interactions co-occur. A strong connection found between co-regulatory actions that activate the discussion and metacognitive acts of planning. In fact this connection accounted for a quarter of the discourse. The co-regulatory activity of "activate" accounts for $82 \%$ of the variance leading to the social-emotional constructs of "contributing to the on-going discussion" either moving a discussion forward by showing acceptance of other's ideas or providing additional information. Finally, there is a strong inter-relationship (92\%) amongst metacognitive activities and socio-emotional interactions with respect to evaluation and Interactive Social Presence, respectively. Efforts to justify and explain one's own approach to delivering bad news are found to co-occur with moving the discussion forward. Justifying and explaining each point is very important for shared regulation as the next point of discussion branches from there with a common understanding and acceptance from other group members. This finding is akin to a productive tumble-weed effect where discussion points keep rolling by providing detailed, easy to understand and thought provoking points. The connection between co-regulatory activities and social emotional constructs has important implications for instruction. Facilitators, be they teachers, tutors or other students, can help develop a shared understanding of the task through simple acts of activating a new construct in line with a previous direction that was introduced into the dialogue.

In addition to adding to the theoretical and methodological discussions of regulatory processes we have provided a unique computer-supported collaborative environment that served an international group of medical students and facilitators in achieving their learning objectives. The environment provided just enough structure and constraints to support and expand face-toface interactions over the Internet by using audio, video, and text chats. The environment provides a repository for video case exemplars that are used to trigger group discourse about difficult medical issues. This simple tool could be used to augment discussions more globally where multiple perspective taking can lead to better practices.

\section{Acknowledgment}

This research was supported by grants from the Social Sciences and Humanities Research Council of Canada.

\section{References}

Alexander, J. M., Carr, M., \& Schwanenflugel, P. J. (1995). Development of metacognition in gifted children: Directions for future research. Developmental Review, 15(1), 1-37.

Alexander, P., Dinsmore, D., Parkinson, M., \& Winters, F. (2011). The interplay of academic domains and self-regulated learning. Handbook of self-regulation of learning and performance. New York: Routledge.

Anderson, T. (2004). Teaching in an online learning context. In T. Anderson \& F Elloumi (Eds.), Theory and practice of online learning (pp. 273). Athabasca University.

Arbaugh, J. B. (2005). Is there an optimal design for on-line MBA courses? Academy of Management Learning E' Education, 4(2), 135-149.

Azevedo, R. (2009). Theoretical, conceptual, methodological, and instructional issues in research on metacognition and self-regulated learning: A discussion, Metacognition and Learning, 4(1), 87-95.

Azevedo, R., Moos, D., Johnson, A., \& Chauncey, A. (2010). Measuring cognitive and metacognitive regulatory processes used during hypermedia learning: Issues and challenges. Educational Psychologist, 45(4), 210-223.

Baile, W. F., Buckman, R, Lenzi, R. Glober, G., Beale, E. A. \& Kudelka, A. P. (2000) SPIKES-A six-step protocol for delivering bad news: Application to the patient with cancer. The Oncologist, 5(4), 302-311.

Baker, L., \& Brown, A. L. (1984). Cognitive monitoring in reading. Understanding Reading Comprehension, 21-44.

Bandura, A. (1977). Self-efficacy: Toward a unifying theory of behavioral change. Psychological Review, 84(2), 191.

Barrows, H. S., \& Tamblyn, R. M. (1986). Problem-based learning: An approach to medical education. New York: Springer.

Buckman, R. (1984). Breaking bad news: Why is it still so difficult? British Medical Journal (Clinical research ed.), 288(6430), 1597.

Buckman, R. A. (2005). Breaking bad news: The s-p-i-k-e-s strategy. Community Oncology, 2(2), 138-142.

Chan, C. K. (2012). Co-regulation of learning in computer-supported collaborative learning environments: A discussion. Metacognition and Learning, 7(1), 63-73.

Chi, M. T. H., Glaser, R., \& Farr, M. J. (1988). The nature of expertise. Hillsdale, NJ: Erlbaum, pp. ix-Xvii.

Corno, L., \& Mandinach, E. B. (1983). The role of cognitive engagement in classroom learning and motivation. Educational Psychologist, 18(2), 88-108.

Cruz-Panesso, I., Lajoie, S. P., \& Lachapelle, K. (2013). Team cognitive task analysis: The hidden layers of team coordination. Royal College's Simulation Summit, Promoting Professional Proficiencies, Vancouver.

Dinsmore, D. L., Alexander, P. A., \& Loughlin, S. M. (2008). Focusing the conceptual lens on metacognition, self-regulation, and self-regulated learning. Educational Psychology Review, 20(4), 391-409.

D’Mello, S., Olney, A., \& Person, N. (2010). Mining collaborative patterns in tutorial dialogues. JEDM-Journal of Educational Data Mining, 2(1), 2-37.

D’Mello, S., Taylor, R., \& Graesser, A. (2007). Monitoring affective trajectories during complex learning. In D. Mcnamara \& G. Trafton (Eds.), Proceedings of the 29th annual cognitive science society (pp. 203-208). Austin, TX: Cognitive Science Society.

Fishel, R. S., \& Hochman, J. (2009). Breaking bad news to patients. In A. Gabrielli, J. Layon, \& M. Yu (Eds.), Civetta, Taylor \& Kirby's critical care (pp. 38-54). Lippincott, WIlliams \& Wicons.

Flavell, J. H. (1979). Metacognition and cognitive monitoring: A new area of cognitive-developmental inquiry. American Psychologist, 34, 906-911.

Fox, N. A., \& Calkins, S. D. (2003). The development of self-control of emotion: Intrinsic and extrinsic influences. Motivation and Emotion, 27(1), 7-26.

Garrison, D. R., Anderson, T., \& Archer, W. (2000). Critical inquiry in a text-based environment: Computer conferencing in higher education. The Internet and Higher Education, 2, 87-105.

Gross, J. J., \& Thompson, R. A. (2007). Emotion regulation: Conceptual foundations. Handbook of Emotion Regulation, 3, 24.

Hadwin, A. F., Järvelä, S., \& Miller, M. (2011). Self-regulated, co-regulated, and socially shared regulation of learning. Handbook of self-regulation of learning and performance (pp. 65-84)

Hadwin, A. \& Järvelä, S. (2011). Introduction to a special issue on social aspects of self-regulated learning: Where social and self meet in the strategic regulation of learning. Teachers College Record, 113(2), 235-239.

Hadwin, A., \& Oshige, M. (2011). Self-regulation, coregulation, and socially shared regulation: Exploring perspectives of social in self-regulated learning theory. Teachers College Record, 113(6), 240-264.

Hadwin, A., Wozney, L., \& Pontin, O. (2005). Scaffolding the appropriation of selfregulatory activity: A socio-cultural analysis of changes in teacher-student discourse about a graduate research portfolio. Instructional Science, 33(5-6), 413-450. http://dx.doi.org/10.1007/s11251-005-1274-7. 
Hmelo-Silver, C. E. (2004). Problem-based learning: What and how do students learn? Educational Psychology Review, 16(3), 235-266.

Hmelo-Silver, C. E., \& DeSimone, C. (2013). Problem-based learning: An instructional model of collaborative learning. The international handbook of collaborative learning (pp. 370-386).

Hmelo-Silver, C. E., \& Barrows, H. S. (2006). Goals and strategies of a problem-based learning facilitator. Interdisciplinary Journal of Problem-based Learning, 1(1), 4.

Hmelo-Silver, C. E., \& Barrows, H. S. (2008). Facilitating collaborative knowledge building. Cognition and Instruction, 26, 48-94.

Hwang, A., \& Arbaugh, J. B. (2006). Virtual and traditional feedback-seeking behaviors: Underlying competitive attitudes and consequent grade performance. Decision Sciences Journal of Innovative Education, 4(1), 1-28.

Iiskala, T., Vauras, M., Lehtinen, E., \& Salonen, P. (2011). Socially shared metacognition of dyads of pupils in collaborative mathematical problemsolving processes. Learning and Instruction, 21(3), 379-393.

Järvelä, S., \& Hadwin, A. F. (2013). New frontiers: Regulating learning in CSCL. Educational Psychologist, 48(1), 25-39.

Järvenoja, H., \& Järvelä, S. (2009). Emotion control in collaborative learning situations: Do students regulate emotions evoked by social challenges. British Journal of Educational Psychology, 79(3), 463-481.

Kaplan, A. (2008). Clarifying metacognition, self-regulation, and self-regulated learning: What's the purpose? Educational Psychology Review, 20(4), 477-484.

Khosa, D. K. (2014). Processes of metacognitive regulation and knowledge coconstruction in case-based collaborative learning at university (Doctoral dissertation, Murdoch University).

Kinnebrew, J. S., Segedy, J. R., \& Biswas, G. (2014). Analyzing the temporal evolution of students' behaviors in open-ended learning environments. Metacognition and Learning, 1-29.

Lajoie, S. P. (2008). Metacognition, self regulation, and self-regulated learning: A Rose by any other Name? Educational Psychology Review, 20(4), 469-475. http:/ dx.doi.org/10.1007/s10648-008-9088-1.

Lajoie, S. P., \& Poitras, E. (2014). Macro and micro strategies for metacognition and co-regulation in the medical tutoring domain. In R. Sottilare, X. Hu, \& A. Graesser (Eds.), Design recommendations for adaptive intelligent tutoring systems: Adaptive instructional management (Vol. 2, pp. 151-168). Orlando, FL: U.S. Army Research Laboratory.

Lajoie, S. P., Garcia, B. C., Berdugo, G. C., Marquez, L., Espíndola, S., \& Nakamura, C. (2006). The creation of virtual and face-to-face learning communities: An international collaborative experience. Journal of Educational Computing Research, 35, 163-180.

Lajoie, S. P., Hmelo-Silver, C., Wiseman, J., Chan, L. K., Lu, J., Khurana, C., et al. (2014). Using online digital tools and video to support international problem-based learning. Interdisciplinary Journal of Problem Based Learning, 8(2). http:// dx.doi.org/10.7771/1541-5015.1412.

Lajoie, S. P., \& Lu, J. (2012). Supporting collaboration with technology: Does shared cognition lead to co-regulation in medicine? Metacognition and Learning, 7(1), 45-62.

Lopes, P. N., Salovey, P., Côté, S., Beers, M., \& Petty, R. E. (2005). Emotion regulation abilities and the quality of social interaction. Emotion, 5(1), 113.

Loyens, S. M., Magda, J., \& Rikers, R. M. (2008). Self-directed learning in problembased learning and its relationships with self-regulated learning. Educational Psychology Review, 20(4), 411-427.

McCaslin, M. (2004). Coregulation of opportunity, activity, and identity in student motivation: Elaborations on Vygotskian themes. Big Theories Revisited, 4, 249-274.

McCaslin, M. (2009). Co-regulation of student motivation and emergent identity. Educational Psychologist, 44(2), 137-146.

McCaslin, M., \& Hickey, D. T. (2001). Self-regulated learning and academic achievement: A Vygotskian view. Self-regulated Learning and Academic Achievement: Theoretical Perspectives, 2, 227-252.

Meijer, J., Veenman, M. V. J., \& van Hout-Wolters, B. H. A. M. (2006). Metacognitive activities in text-studying and problem-solving: Development of a taxonomy. Educational Research and Evaluation, 12(3), 209-237. http://dx.doi.org/10.1080/ 13803610500479991.

Palinscar, A. S., \& Brown, A. L. (1984). Reciprocal teaching of comprehensionfostering and comprehension-monitoring activities. Cognition and Instruction, $1(2), 117-175$.

Pekrun, R., \& Linnenbrink-Garcia, L. (Eds.). (2014). International handbook of emotions in education. Routledge.

Pintrich, P. R. (2004). A conceptual framework for assessing motivation and selfregulated learning in college students. Educational Psychology Review, 16(4), 385-407.

Pintrich, P. R. (2000). The role of goal orientation in self-regulated learning. In M. Boekaerts, P. Pintrich, \& M. Zeidner (Eds.), Handbook of self-regulation (pp. 451-502). San Diego, CA: Academic.

Poitras, E. G., \& Lajoie, S. P. (2013). A domain-specific account of self-regulated learning: The cognitive and metacognitive activities involved in learning through historical inquiry. Metacognition and Learning, 8(3), 213-234.
Richardson, J. C., \& Swan, K. (2003). Examing social presence in online courses in relation to students' perceived learning and satisfaction.

Rimé, B. (2007). The social sharing of emotion as an interface between individual and collective processes in the construction of emotional climates. Journal of Social Issues, 63(2), 307-322.

Rogat, T. K., \& Linnenbrink-Garcia, L. (2011). Socially shared regulation in collaborative groups: An analysis of the interplay between quality of social regulation and group processes. Cognition and Instruction, 29(4), 375-415.

Rovai, A. P. (2002). Building sense of community at a distance. The International Review of Research in Open and Distance Learning, 3(1).

Schraw, G., \& Moshman, D. (1995). Metacognitive theories. Educational Psychology Review, 7(4), 351-371.

Schunk, D. H. (2005). Self-regulated learning: The educational legacy of Paul R. Pintrich. Educational Psychologist, 40, 85-94.

Schwartz, N. H., Scott, B. M., \& Holzberger, D. (2013). Metacognition: A closed-loop model of biased competition-evidence from neuroscience, cognition, and instructional research. In R. Azevedo \& V. Aleven (Eds.), Internationa handbook of metacognition and learning technologies (pp. 79-94). Springer.

Sise, M. J., Sise, C. B., Sack, D. I., \& Goerhing, M. (2006). Surgeons' attitudes about communicating with patients and their families. Current Surgery, 63(3), $213-218$

Stevens, M. J., \& Campion, M. A. (1994). The knowledge, skill, and ability requirements for teamwork: Implications for human resource management. Journal of Management, 20(2), 503-530.

Thompson, L., \& Fine, G. A. (1999). Socially shared cognition, affect, and behavior: A review and integration. Personality and Social Psychology Review, 3(4), 278-302.

Tice, D. M., \& Bratslavsky, E. (2000). Giving in to feel good: The place of emotion regulation in the context of general self-control. Psychological Inquiry, 11(3) 149-159.

Volet, S., \& Summers, M. (2013). Interpersonal regulation in collaborative learning activities: Reflections on emerging research methodologies. In S. Volet \& M Vauras (Eds.), Interpersonal regulation of learning and motivation: Methodological advances (pp. 204-220). Oxon: Routledge.

Volet, S., Summers, M., \& Thurman, J. (2009). High-level co-regulation in collaborative learning: How does it emerge and how is it sustained? Learning and Instruction, 19(2), 128-143.

Volet, S., \& Vauras, M. (2013). Interpersonal Regulation of Learning and Motivation: Methodological Advances. Routledge.

Volet, S. E., Vauras, M., Khosa, D., \& Iisakala, T. (2013). Metacognitive regulation in collaborative learning: Theoretical advances and methodological contextualizations. Interpersonal regulation of learning and motivation: Methodological advances. London: Routledge.

Volet, S., Vauras, M., \& Salonen, P. (2009). Self-and social regulation in learning contexts: An integrative perspective. Educational Psychologist, 44(4), 215-226.

Vygotsky, L. S. (1978). Mind and society: The development of higher mental processes

Webb, N. M., Ing, M., Kersting, N., \& Nemer, K. M. (2006). Help seeking in cooperative learning groups. Strategic help seeking: Implications for learning and teaching (pp. 45-115).

Wertsch, J., \& Stones, C. (1985). The concept of internalization in Vygotsky's account of the genesis of higher mental functions. In J. Wertsch (Ed.), Culture, communication, and cognition: Vygotskian perspectives (pp. 162-182). New York: Cambridge University Press.

Wilkinson, L., \& Friendly, M. (2009). The history of the cluster heat map. The American Statistician, 63(2).

Williams, E. A., Duray, R., \& Reddy, V. (2006). Teamwork orientation, group cohesiveness, and student learning: A study of the use of teams in online distance education. Journal of Management Education, 30(4), 592-616.

Winne, P. H., \& Hadwin, A. F. (2008). The weave of motivation and self-regulated learning. In D. H. Schunk \& B. J. Zimmerman (Eds.), Motivation and self-regulated learning: Theory, research, and applications (pp. 297-314). Mahwah, NJ: Lawrence Erlbaum Associates.

Yin, R. K. (2009). Case study research: Design and methods (Vol. 5). Sage.

Yoo, Y., Kanawattanachai, P., \& Citurs, A. (2002). Forging into the wired wilderness: A case study of a technology-mediated distributed discussion-based class. Journal of Management Education, 26(2), 139-163.

Zimmerman, B. J. (1986). Becoming a self-regulated learner: Which are the key subprocesses? Contemporary Educational Psychology, 11(4), 307-313.

Zimmerman, B. J. (2006). Development and adaptation of expertise: The role of selfregulatory processes and beliefs. In K. A. Ericsson, N. Charness, P. J. Feltovich, \& R. R. Hoffman (Eds.), The Cambridge handbook of expertise and expert performance (pp. 705-722). Newyork: Cambridge University Press.

Zimmerman, B. J. (2008). Investigating self-regulation and motivation: Historica background, methodological developments, and future prospects. American Educational Research Journal, 45(1), 166-183.

Zimmerman, B. J., \& Schunk, D. H. (2011). Handbook of self-regulation of learning and performance. Taylor \& Francis.

Zimmerman, B. J., \& Schunk, D. H. (2001). Self-regulated learning and academic achievement: Theoretical perspectives. Mahwah, N.J.: Erlbaum. 